\title{
Simultaneous removal of basic dyes from binary systems by modified orange peel and modeling the process by an intelligent tool
}

\author{
Hedieh Khalili ${ }^{a}$, Azadeh Ebrahimian Pirbazarib, ${ }^{\mathrm{b}, 1}$, Fatemeh Esmaeili Khalil Saraei ${ }^{\mathrm{b}}$, Seyed \\ Hamed Mousavi ${ }^{\mathrm{a}, 2}$ \\ aSeparation Processes \& Nanotechnology Lab, Caspian Faculty of Engineering, College of \\ Engineering, University of Tehran, Tehran, Iran \\ ${ }^{b}$ Hybrid nanomaterials and Environment Lab, Fouman Faculty of Engineering, College of \\ Engineering, University of Tehran, P.O. Box 43515-1155, Fouman 43516-66456, Iran
}

\begin{abstract}
:
This study presents the consecutive modification of orange peel (OP) by $\mathrm{NaOH}$ and sodium dodecyl sulfate (SDS) for simultaneous elimination of basic dyes from binary system and modelling the adsorption process using an intelligent tool. The natural and modified biosorbents were characterized by variety of analyses such as: Field Emission Scanning Electron Microscopy (FESEM) with energy Dispersive X-ray (EDX), $\mathrm{N}_{2}$ physisorption and Fourier transform infrared spectroscopy (FTIR) techniques. The influence of various variables on dye removal like $\mathrm{pH}$, quantity of biosorbents, dyes concentration, contact time and temperature in binary system were investigated and optimized by an artificial neural network (ANN) model as an intelligent tool. The optimum quantity of the sorbent was found to be $0.30 \mathrm{~g}$ for orange peel (OP) and $0.25 \mathrm{~g}$ for $\mathrm{NaOH}-$ treated OP (NOP) and SDS-decorated NOP (SNOP) at $\mathrm{pH}=7$. The Kinetics and thermodynamics investigations showed that the removal of dyes obeyed the pseudo-second order kinetic model and were spontaneous and exothermic in nature. Moreover, in order to describe the mechanism of sorption process, desorption studies of dyes were carried out. The desorption percentages of methylene blue (MB) in water and $\mathrm{HCl}$ were found to be in the range of $1.93 \%-4.76 \%$ and 18.87 $\%-28.76 \%$, respectively; in addition, the desorption percentages of crystal violet (CV) in water and $\mathrm{HCl}$ were obtained to be in the range of $4.11 \%-7.41 \%$ and $32.84 \%-43.00 \%$, respectively; which could be a recommendation ion exchange or electrostatic attachment of dyes onto biosorbents. The ANN predictions matched with the experimental data very well
\end{abstract}

\footnotetext{
${ }^{1}$ Corresponding author1: .E-mail address: aebrahimian@ut.ac.ir (A. Ebrahimian Pirbazari).

${ }^{2}$ Corresponding author2: .E-mail address: mhmousavi@ut.ac.ir (S.H. Mousavi).

Hedieh Khalili (hediye.khalili@ut.ac.ir) and Fatemeh Esmaeili Khalil Saraei (f.esmaeili.kh@ut.ac.ir).
} 
$\left(0.95308<\mathrm{R}^{2}<0.99191\right.$ and $0.98335<\mathrm{R}^{2}<0.99773$ for $\mathrm{MB}$ and $\mathrm{CV}$, respectively) which indicated high accuracy of the ANN model. In addition, the relative importance of each parameter was calculated by Garson's equation.

Keywords: Binary system; Surfactant modification; Orange peel; Artificial neural network modeling.

\section{Introduction:}

Nowadays, an expansion of contaminant disposal is happening due to the quick industrial development, urbanization and population growth which leads to effect human beings as well as plants and animals [1]. The genotoxic agents are more troublesome due to the possibility of causing heritable disorders. There are different types of pollutants that among them, synthetic dyes are concerning because of their wide application in numerous industries such as pharmaceutical, textile, plastic, cosmetics, tanner, leather, pigments, rubber and paint. Remarkable amounts of contaminated wastewaters are discharged into the surroundings along with wastewater produced during the industrialized process [2-4]. Recently, the removal of dyes from dissipate effluents becomes a serious environmental challenge. There are different types of dyes according to the ionic charge on dye molecules: cationic, anionic and non-ionic dyes, that among them cationic dyes are the most toxic ones [5,6]. Previous studies [7-9] concentrated on single adsorption systems using various adsorbents. Recently, by analyzing wastewater containing dyes, it was observed that many dyes coexist simultaneously; therefore, nowadays researches are focused on multicomponent dye adsorption [10-12]. Thus, finding a cost-effective way to eliminate such effluents from wastewaters has attracted a lot of attention these days [13]. There are two types of methods to treat contaminated effluents: physical and chemical processes [14] which include membrane processes, floatation, coagulation, evaporation, photo-catalytic degradation, sedimentation, micellar enhanced ultra-filtration, adsorption, etc. [15,16]. Adsorption has displayed promising results among all of these methods, and is considered as a practical way to eliminate dyes from aqueous solutions in order to its easiness of design, low price procedure, insensitivity to poisonous contaminants, simplicity of operation and smaller quantity of dangerous substances [17,18]. Various industrial byproducts or natural materials are inexpensive and abundant, for this reason they are assumed to be low-cost adsorbents. These kinds of wastes need 
little processing and can be used after some insignificant treatments. As adsorbent, agricultural wastes like orange peel, apple pomace, wheat straw, tea leaves, banana peel, sawdust, bamboo, etc. have gained more attention [7,19-22]. Generally, agricultural residues require physical and chemical modifications because of their low adsorption capacity [23]. Physical modifications are usually supposed as being incomplex and economical, although they are not commonly used due to their low effectiveness [24,25]. Conversely, chemical treatments are able to improve the properties of adsorbents including larger surface area, higher porosity and expansion of the number of available active sites, and accordingly these methods are preferred by most researchers [26,27]. Treatment with aqueous sodium hydroxide $(\mathrm{NaOH})$ solution has a significant impact on molecular, supramolecular and morphological characteristics of cellulose, causing change in pore structure, stiffness, ease of access, crystallinity, direction of fibrils in cellulosic fibers and unit cell structure [28]. Treatment with $\mathrm{NaOH}$ makes the cellulose fiber surface empty of natural fats and waxes that causes revealing functional groups like $-\mathrm{OH}$ [29]. On the other hand, in recent years, researchers have focused on the application of surfactants for removing dyes and other toxic substances from industrial wastewaters $[30,31]$. Surfactants decrease surface tension of aqueous solutions; they are produced by chemical reaction and do not exist in nature. The surface activity of surfactants originates from the fact that each molecule of surfactants contains both hydrophilic and hydrophobic parts which allow them to adsorb different types of pollutants [32].

The efficiency of adsorption process can be figured out by various modeling techniques like artificial neural networks (ANNs). A many of complex engineering systems could be solved and modeled by using of ANN due to its nonlinearity, reliability, simplicity and robustness. ANN has an inclusive structure and can build a model from the historical data [33,34]; Moreover, it can be employed for modeling of the complex relationships between the sorbent and sorbates in multicomponent aqueous solutions [35].

Present study concentrates on simultaneous removal of basic dyes, Methylene blue (MB) and Crystal violet $(\mathrm{CV})$, on orange peel (OP), sodium hydroxide-treated OP (NOP) and sodium dodecyl sulfate-decorated NOP (SNOP). It should be noted that it is the first time that a plentiful agricultural waste is treated twice and is used as an effective adsorbent in order to simultaneous removal of dyes. Optimization of all the effective parameters such as $\mathrm{pH}$, adsorbent dosage, reaction contact time and initial dyes concentration were carried out and mechanism of adsorption 
was proposed. Furthermore, artificial neural network (ANN) model has been applied for the prediction of removal efficiency of $\mathrm{MB}$ and $\mathrm{CV}$.

\section{Experimental}

\subsection{Materials}

The orange peel (OP) was obtained from a local farm in Iran and used for preparation of the chemically modified biosorbents. These collected materials were cut into small pieces, washed with boiled water to eliminate any adhering dirt and finally dehydrated in the oven at $80{ }^{\circ} \mathrm{C}$ for 12 $\mathrm{h}$ (the color changed from orange to pale-orange). The dehydrated peels were crushed and sieved to achieve an average particle size range of 100-500 $\mu \mathrm{m}$ and kept in air tight container for future use. Basic dyes used in this study, namely, methylene blue (MB) (No.115943) and crystal violet (CV) (No. 115940), were purchased from Merck. Mixed dyes solution with proposed initial dyes concentrations ranged from 20-500 mg. $\mathrm{L}^{-1}$ were prepared. All solutions were prepared with a dye solution of equal concentrations. The $\mathrm{pH}$ of the solutions were set to the wanted value by adding 0.01 mol.L ${ }^{-1} \mathrm{NaOH}$ or $0.01 \mathrm{~mol} . \mathrm{L}^{-1} \mathrm{HCl}$. Methyl orange (MO) was bought from Merck (No.101322). Sodium dodecyl sulfate (SDS) solutions were provided from commercially sample (Merck, 822050) dissolved in distilled water.

\subsection{Preparation of $\mathrm{NaOH}-$ treated orange peel}

OP was treated with sodium hydroxide solution in order to ameliorate the capacity of adsorption of mixed dyes. For this purpose, $10 \mathrm{~g}$ of dried OP was mixed with $200 \mathrm{~mL} \mathrm{NaOH}\left(0.1 \mathrm{~mol}^{-1} \mathrm{~L}^{-1}\right)$ for $6 \mathrm{~h}$. After filtration, the modified sorbent (NOP) was washed thoroughly with deionized water until neutral $\mathrm{pH}$ and after that, the product was dehydrated at $60{ }^{\circ} \mathrm{C}$ in the oven for $8 \mathrm{~h}$. Finally, the prepared sample was kept in air tight vessel to perform elimination tests.

\subsection{Modification of NOP by SDS}

The surface modification is not influential above the critical micellar concentration (CMC). Therefore, the SDS solution was provided below its $\mathrm{CMC}\left(\mathrm{CMC}=0.0082 \mathrm{~mol} . \mathrm{L}^{-1}\right) .5 .7 \times 10^{-3} \mathrm{~g}$ SDS was dissolved in $100 \mathrm{~mL}$ of distilled water and after 10 mins of shaking, $10 \mathrm{~g}$ of NOP was poured to the solution. The prepared solution was shaken at $180 \mathrm{rpm}$ by shaker for $3 \mathrm{~h}$ at $303 \mathrm{~K}$. After that, the SDS-decorated NOP (SNOP) was separated and rinsed with distilled water to reach 
the conductance of filtrate less than $0.05 \mu \mathrm{S}$. The SNOP was dehydrated in oven at $80{ }^{\circ} \mathrm{C}$ for $24 \mathrm{~h}$. The prepared sample then was saved in air tight vessel for further use.

\subsection{Characterization}

Using an X-ray detractor (Siemens, D5000, Germany), the X-ray diffraction (XRD) measurements were collected using $\mathrm{CuK} \alpha$ radiation as the $\mathrm{X}$-ray source. The diffractograms were recorded within the $2 \theta$ range of $20-80^{\circ}$. Using Field Emission Scanning Electron Microscope (FESEM, CamScan MV2300) with an energy dispersive X-ray (EDX, BRUKER Xflash6110), the morphology of the prepared biosorbents was investigated. A nitrogen adsorption system (Belsorp mini) was applied to investigate specific surface area based on nitrogen physisorption. The BET areas were determined by static nitrogen physisorption at $-196{ }^{\circ} \mathrm{C}$ followed by out-gassing at $200{ }^{\circ} \mathrm{C}$ until the pressure was lower than 5 mbar. Fourier transform infrared (FTIR) spectroscope (Perkin ElmerSpectrum 1) in the range of 4000 to $400 \mathrm{~cm}^{-1}$ was employed for functional groups characterization.

\subsection{Adsorption procedure}

Batch elimination tests were determined to make the biosorption equilibrium isotherm data. Each test was carried out in the presence of a fixed mass of OP $(0.3 \mathrm{~g})$, NOP and SNOP $(0.25 \mathrm{~g})$ in 250 $\mathrm{mL}$ glass Erlenmeyer's flasks contains $100 \mathrm{~mL}$ of a mixture of $\mathrm{MB}$ and $\mathrm{CV}$ solutions at a temperature of $30{ }^{\circ} \mathrm{C}$ and $\mathrm{pH}=7$. The process was carried out for temperatures 40 and $50{ }^{\circ} \mathrm{C}$. The primary $\mathrm{pH}$ adjustments were performed by $0.01 \mathrm{~mol} . \mathrm{L}^{-1} \mathrm{NaOH}$ or $0.01 \mathrm{~mol} . \mathrm{L}^{-1} \mathrm{HCl}$ solutions. To prepare the mixed solution, dye solutions were prepared separately in the range of 50-700 mg.L ${ }^{-1}$, mixed in equal volume to obtain dye concentration in the range of 20-500 mg.L ${ }^{-1}$. Adsorption equilibrium was reached after $20 \mathrm{~min}$. After the end of the reaction time, the samples were centrifuged and then the remaining $\mathrm{MB}$ and $\mathrm{CV}$ concentration was measured by a double beam UV-Vis spectrophotometer (Rayleigh UV-2601 UV/VIS spectrophotometer) at $\lambda_{\max }=664 \mathrm{~nm}$ for $\mathrm{MB}$ and $\lambda_{\max }=584 \mathrm{~nm}$ for $\mathrm{CV}$.

In binary solution, the concentration of each dye at time $t$ was calculated from the calibration graphs using the following equation, the removal efficiency of dye " $D$ " has determined:

$R_{D} \%=\frac{C_{0, D}-C_{t, D}}{C_{0, D}} \times 100 \quad \mathrm{D}: \mathrm{MB}$ or $\mathrm{CV}$ 
Where $\mathrm{C}_{0, \mathrm{D}}\left(\mathrm{mg} \cdot \mathrm{L}^{-1}\right)$ is the initial concentration of dye " $\mathrm{D}$ " and $\mathrm{C}_{\mathrm{t}, \mathrm{D}}\left(\mathrm{mg} \cdot \mathrm{L}^{-1}\right)$ is its concentration at time t.

The following equations were used to compute the adsorbed amount of dye " $D$ " at equilibrium qeq, $\mathrm{D}\left(\mathrm{mg} \cdot \mathrm{g}^{-1}\right)$ and at time $\mathrm{t} \mathrm{q}_{\mathrm{t}, \mathrm{D}}\left(\mathrm{mg} \cdot \mathrm{g}^{-1}\right)$ :

$q_{e, D}=\frac{\left(C_{0, D}-C_{e, D}\right) \times V}{w}$

$q_{t, D}=\frac{\left(C_{0, D}-C_{t, D}\right) \times V}{w}$

Where $\mathrm{C}_{e, \mathrm{D}}\left(\mathrm{mg} \cdot \mathrm{L}^{-1}\right)$ is the concentrations at equilibrium of dye " $\mathrm{D}$ ", $\mathrm{V}(\mathrm{L})$ is the volume of the dye mixture and $\mathrm{w}(\mathrm{g})$ is the quantity of the modified orange peel.

\subsection{Kinetic assays}

The adsorption kinetics of binary system of $\mathrm{MB}$ and $\mathrm{CV}$ onto the prepared biosorbents was evaluated. For this purpose, $100 \mathrm{~mL}$ of mixed dyes solution with diverse initial concentrations (100-300 mg. $\left.\mathrm{L}^{-1}\right)$ were provided to prepare the mixed solution in the range of $50-250 \mathrm{mg} . \mathrm{L}^{-1}$. Kinetic studies were carried out by contacting prepared solutions with $0.3 \mathrm{~g}$ of OP and $0.25 \mathrm{~g}$ of NOP and SNOP at room temperature under constant stirring. At fixed time intervals, the sorbents were extracted from the solution and the absorption measured at the $\lambda_{\max }$ for each dye. The kinetic parameters are widely favorable to predict the sorption rate of the simultaneous $\mathrm{MB}$ and $\mathrm{CV}$ adsorption onto the adsorbents. Moreover, these parameters give crucial information to progress and model the biosorption processes.

The Lagergren pseudo-first-order kinetic model can be expressed as [36]:

$\frac{d_{q}}{q_{e, D}-q_{D}}=k_{1, D} d t$

Integrating this equation considering the boundary conditions $\mathrm{t}=0$ to $\mathrm{t}=\mathrm{t}$ and $\mathrm{q}=0$ to $\mathrm{q}=\mathrm{q}_{\mathrm{t}}$ gives:

$\ln \left(q_{e, D}-q_{t, D}\right)=\ln q_{e, D}-k_{1, D} t$

Where $\mathrm{q}_{\mathrm{t}}, \mathrm{D}$ and $\mathrm{q}_{\mathrm{e}}, \mathrm{D}$ are the quantities of dye $\left(\mathrm{mg}^{\mathrm{g}} \mathrm{g}^{-1}\right)$ at time $\mathrm{t}(\mathrm{min})$ and at equilibrium, respectively; and $\mathrm{k}_{1, \mathrm{D}}$ is the rate constant of pseudo-first-order model $\left(\mathrm{min}^{-1}\right)$. Using linearized plot of $\ln \left(q_{e}, D-q_{t}, D\right)$ vs $t$, the validity of the model can be discovered. Additionally, the rate constant of pseudo-first-order adsorption can be calculated from the slope of the plot.

The pseudo-second-order equation can be represented as: 
$\frac{d_{q, D}}{\left(q_{e, D}-q_{t, D}\right)^{2}}=k_{2, D} d t$

The integrated linear from the above equation, considering the boundary conditions $\mathrm{t}=0$ to $\mathrm{t}=\mathrm{t}$ and $\mathrm{q}=0$ to $\mathrm{q}=\mathrm{q}_{\mathrm{t}, \mathrm{D}}$, can be written as:

$\frac{1}{q_{e, D}-q_{t, D}}-\frac{1}{q_{e, D}}=k_{2, D} t$

Rewriting Eq 7 gives Eq 8:

$\frac{t}{q_{t, D}}=\frac{1}{k_{2, D} q_{e, D}^{2}}+\frac{t}{q_{e, D}}$

Where $\left(\mathrm{q}_{\mathrm{e}}, \mathrm{D}\right)$ is the theoretical equilibrium capacity and $\mathrm{k}_{2, \mathrm{D}}$ is the second-order constant $\left(\mathrm{g} \cdot \mathrm{mg}^{-1} \cdot \mathrm{min}^{-1}\right.$ ) which can be calculated from the slope and intercept of plot $t / q_{t, D}$ versus $t$, respectively.

\subsection{Determination point of zero charge $\mathbf{p H}\left(\mathrm{pH}_{\mathrm{pzc}}\right)$}

To determine $\mathrm{pH}_{\mathrm{pzc}}, 1000 \mathrm{~mL} \mathrm{NaCl}$ solution $\left(0.01\right.$ mol.L $\mathrm{L}^{-1)}$ was provided and its $\mathrm{pH}$ value was adjusted in the range of $1-10$ by adding $\mathrm{HCl}$ or $\mathrm{NaOH}\left(0.1 \mathrm{~mol}^{-1}\right)$. Afterward, $0.1 \mathrm{~g}$ of each prepared adsorbent was inserted to $50 \mathrm{~mL} \mathrm{NaCl}\left(0.01\right.$ mol. $\left.\mathrm{L}^{-1}\right)$ and kept for $96 \mathrm{~h}$. Finally, graphs were plotted for $\mathrm{pH}_{\text {final }} \mathrm{vs} \mathrm{pH}_{\text {initial }}$.

\section{Results and Discussion}

\subsection{FESEM/EDX analysis}

FESEM micrographs of the prepared samples with magnification of $5 \mu \mathrm{m}$ are presented in Fig. 1A. After treatment of OP with $\mathrm{NaOH}$, the porosity and irregular structure of NOP extended, which may be due to the removal of natural fats and waxes from the cellulose fiber surfaces [29] and leads to a significant increase in the adsorption capacity of this biosorbent. The surface of SNOP is rougher compared to the NOP and it may be due to the surfactant can change the physicochemical features of the adsorbents [30]. Therefore, it can be concluded that after decoration of NOP by SDS, the pores of NOP are occupied with SDS molecules and the SNOP surface appears to be more homogeny compared to the NOP. The EDX analysis was used to determine the chemical composition of the biosorbents in which the results were presented in Fig. 1B. The EDX 
analysis data display that $\mathrm{C}, \mathrm{O}, \mathrm{Fe}, \mathrm{S}, \mathrm{P}, \mathrm{K}$ and $\mathrm{Ca}$ elements are presented over the testing area (Fig. 1B). It is obvious that after NOP decoration with SDS, the amount of sulphur atom is increased to $0.33 \%$ that indicates the presence of SDS on the surface of NOP.

(A)
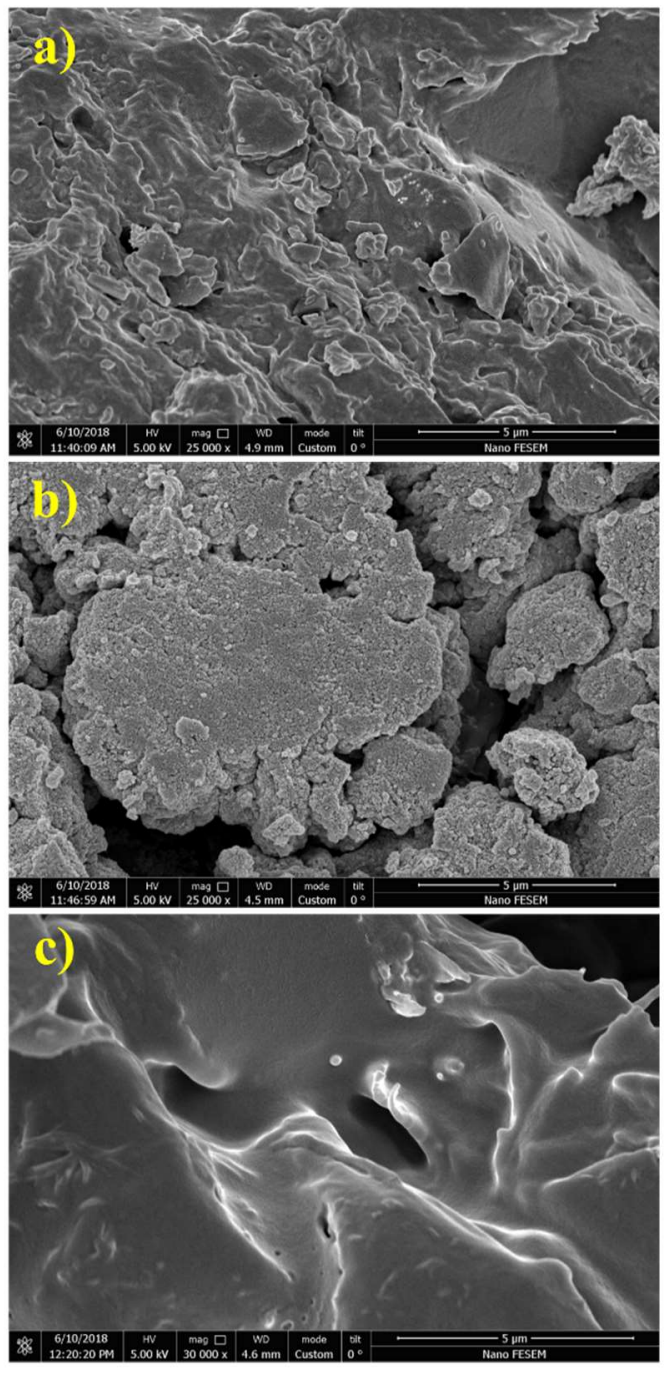

(B)
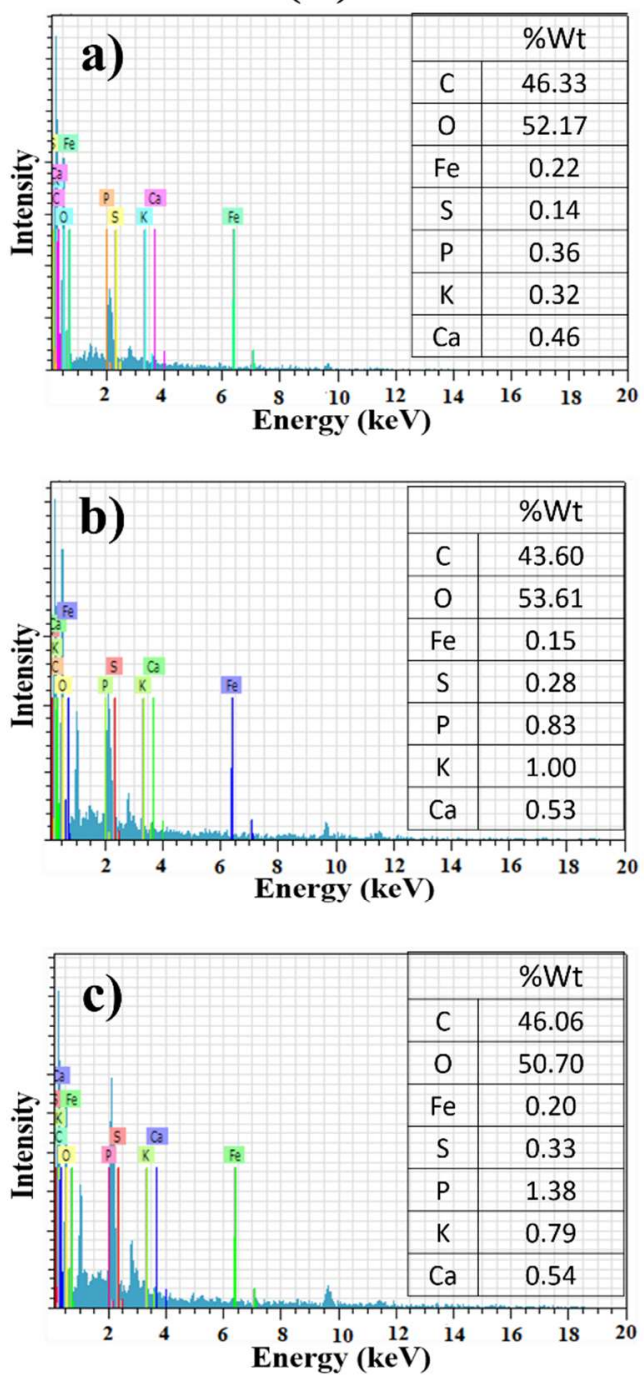

Fig.1. A) FESEM images of a) OP, b) NOP and c) SNOP and B) EDX patterns of a) OP, b) NOP and c) SNOP

\section{2. $\mathrm{N}_{2}$ physisorption analysis}

In the present work, Brunauer-Emmett-Teller (BET) model was used to obtain the specific surface area, pore volumes and pore sizes of the prepared biosorbents based on $\mathrm{N}_{2}$ physiosorption (Table 1 and Fig. S1). Compared to the IUPAC classification [37], the sorption isotherms of the prepared 
samples are the same as type IV (a). The textural and structural parameters of OP, NOP and SNOP biosorbents are presented in Fig. S1. It should be mentioned that Barrett-Joyner-Halenda (BJH) model was used to investigate pore diameter. After treatment by $\mathrm{NaOH}$, the value of the BET surface area decreased compared to OP due to entrap of $\mathrm{NaOH}$ in the micropore area and causes significant change in the structure of the biosorbent and reduces its ultimate surface area [38]. Furthermore, it was observed that after treatment with $\mathrm{NaOH}$, the pore size of OP increased from 12.431 to $20.183 \mathrm{~nm}$. On the other hand, it was found out that the surface area of SNOP was 2.814 $\mathrm{m}^{2} \cdot \mathrm{g}^{-1}$. This enhancement may be due to the general characteristics of micelle formation, solubilization, wetting and adsorption. Surfactant molecules are able to organize themselves appropriately, thus, naturally being amphipathic, surfactant-modified sorbents possess improved surface area and wetting (oil or water wet). Additionally, selective adsorption happens facilely due to the electrostatic interactions [30].

Table 1. The textural parameters of the prepared samples

\begin{tabular}{cccc}
\hline Sorbent & $\begin{array}{c}\text { BET surface area } \\
\left(\mathrm{m}^{2} \cdot \mathrm{g}^{-1}\right)\end{array}$ & $\begin{array}{c}\text { Pore volume } \\
\left(\mathrm{cm}^{2} \cdot \mathrm{g}^{-1}\right)\end{array}$ & $\begin{array}{c}\text { Pore size } \\
(\mathrm{nm})\end{array}$ \\
\hline OP & 1.3811 & 0.0042922 & 12.431 \\
NOP & 0.9154 & 0.0046192 & 20.183 \\
SNOP & 2.8140 & 0.0072586 & 10.318 \\
\hline
\end{tabular}

\subsection{FTIR analysis}

Fig. S2 shows the FTIR spectra of the prepared sorbents in the range of $400-4000 \mathrm{~cm}^{-1}$. The vibration at $3400 \mathrm{~cm}^{-1}$ is ascribed to vibrational modes of hydroxyl groups $(-\mathrm{OH})$ attend to the different hydrogen bonding (inter and intra) of polymeric compounds including carboxylic acids, alcohols and phenols as in lignin, cellulose and pectin [39]. By attending to the FTIR spectra, it is obvious that there are two peaks at 2920 and $2850 \mathrm{~cm}^{-1}$ that can be ascribed to the C-H stretch vibration which is originated from the surface of the biosorbents [40]. The observed peak at 1709 $\mathrm{cm}^{-1}$ is due to the $\mathrm{C}=\mathrm{O}$ stretch vibration which is totally obvious in the spectrum of OP (Fig. S2(a)) [41]. Moreover, the peaks detected at $1617 \mathrm{~cm}^{-1}$ and $1041 \mathrm{~cm}^{-1}$ are due to $\mathrm{C}=\mathrm{C}$ aromatic and $\mathrm{C}$ $\mathrm{H}$, respectively [42]. It should be noted that vibrations at 3599 and $2900 \mathrm{~cm}^{-1}$ can be allocated to the $-\mathrm{CH}_{2}$ group from SDS and peak at $1244 \mathrm{~cm}^{-1}$ can be attributed to $-\mathrm{SO}_{3}$ stretching vibration [43]. However, regarding to FTIR spectrum of OP (Fig. S2(a)), intense vibrations are observed at 
3599, 2900 and $1244 \mathrm{~cm}^{-1}$, hence, using FTIR analysis, the presence of SDS molecules could not be identified. Generally, presence of these peaks indicates that the prepared samples possess various functional groups that simplify the adsorption of dyes through hydrogen bonds [9,12]. However, the FT-IR spectra of NOP and SNOP after dyes adsorption were found to exhibit similar functional groups due to the domination of the functional groups of OP in this sorbent as the major component in these materials.

\subsection{Effect of $\mathrm{pH}$ on simultaneous removal of $\mathrm{MB}$ and $\mathrm{CV}$}

One of the effective factors in the dye adsorption process is the $\mathrm{pH}$ of solution. The charge of the adsorbent surface, the solution chemistry and functional groups present on the active sites depend strongly to $\mathrm{pH}$ of solution [44]. Consistent with the obtained results in Fig. 2, by increasing the $\mathrm{pH}$ of the mixed dyes solution from 2 to 10, the removal percentages increase. Low sorption at lower $\mathrm{pH}$ values could be as a result of the electrostatic repulsion between the cationic adsorbate and adsorbent. The linear range of $\mathrm{pH}$ sensitivity, the adsorption capacity and the type of active centers of the surface can be studied by point of zero charge $\mathrm{pH}\left(\mathrm{pH}_{\mathrm{pzc}}\right)$ [45]. When the $\mathrm{pH}$ of solution is lower than $\mathrm{pH}_{\mathrm{pzc}}\left(\mathrm{pH}<\mathrm{pH}_{\mathrm{pzc}}\right)$, the adsorbent surface becomes positively charged that leads to an electrostatic repulsion between dyes cations and the biosorbents which reduces the removal efficiency. Furthermore, the concentration of $\mathrm{H}^{+}$ions in acidic $\mathrm{pH}$ is remarkable which compete with $\mathrm{MB}$ and $\mathrm{CV}$ cations for active sites onto the prepared biosorbents. Reversely, at $\mathrm{pH}>\mathrm{pH}_{\mathrm{pzc}}$, the presence of $-\mathrm{COOH}$ and $-\mathrm{OH}$ groups on the adsorbents surface, makes it negative, and, therefore, the $\mathrm{MB}$ and $\mathrm{CV}$ cations can be easily adsorbed onto the surface of the sorbents by electrostatic attraction forces [46]. Fig. 2 shows that the \% removal of MB is more than of CV on the prepared sorbents and it can be explained according to Xiong et al work [47]. The adsorption behavior of two organic dyes, namely, crystal violet $(\mathrm{CV}$, triphenylmethane dye of symmetric structure) and methylene blue (MB, azo dye of linear structure), were investigated, characterized and differentiated at the silica/water interface at two range of concentrations using the total internal reflection induced near field evanescent wave (TIR-NFEW) platform. They observed diffusion and absorption processes for $\mathrm{MB}$ and $\mathrm{CV}$ adsorption on the sorbent. MB dye showed faster diffusion speed than $\mathrm{CV}$ because the symmetric structure of $\mathrm{CV}$ is larger in size than the linear MB structure, which leads to a corresponding larger space hindrance and a slower diffusion speed for $\mathrm{CV}$. For the second absorption step, $\mathrm{CV}$ had nearly the same interaction speed as MB. The two 
interactions similar to the low concentration stage took place for both $\mathrm{CV}$ and $\mathrm{MB}$ at the high concentration stage as well. They proposed molecular aligned-mechanism to describe the interfacial interaction process for both $\mathrm{CV}$ and $\mathrm{MB}$ that includes molecular reactions involving electrostatic attraction and H-bonds of functional groups. In our work, at first, both CV and MB molecules interacted with the accessible functional groups through strong electrostatic attraction and other functional groups on the sorbents were occupied and saturated with dye molecules at high concentrations through H-bonds. Also, we observed higher \% removal for MB and CV onto NOP and SNOP due to the presence of more functional groups on OP after treatment by $\mathrm{NaOH}$ and SDS. The $\mathrm{pH}_{\mathrm{pzc}}$ value of OP was found to be 3.7 and this value for NOP and SNOP were found to be 6.8 (Fig. $2 \mathrm{~d}$ ). Thus, due to the neutral $\mathrm{pH}$ ranges (6.0-7.0) of water and wastewaters, the adsorption studies were performed at the optimum $\mathrm{pH}$ 7.0.
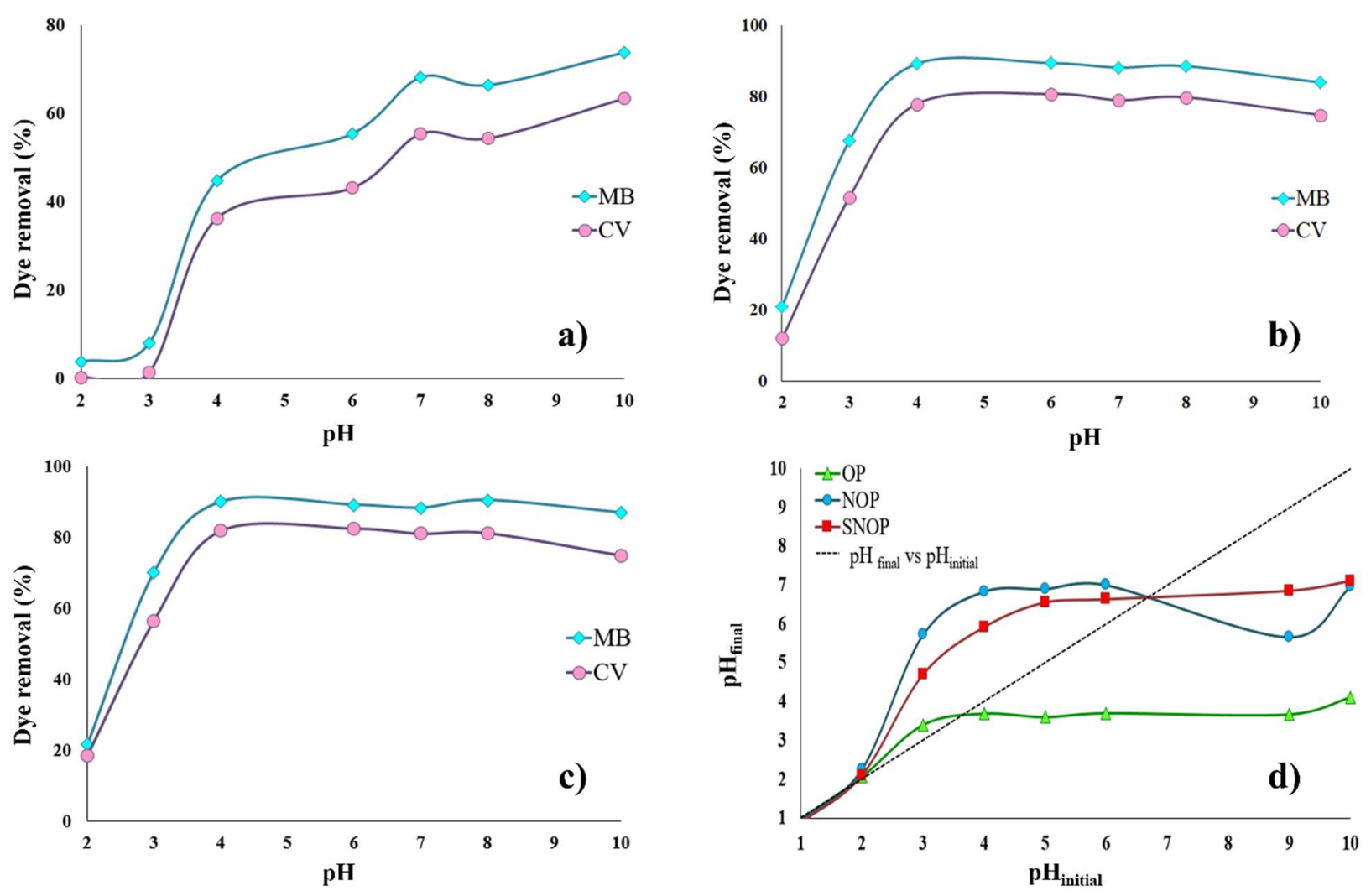

Fig 2. Effect of $\mathrm{pH}$ of solution on simultaneous removal of $\mathrm{MB}$ and $\mathrm{CV}$ dyes by a) $\mathrm{OP}, \mathrm{b}$ ) NOP and c) SNOP. d) Plot for determination of point of zero charge of the prepared sorbents. 


\subsection{Effect of adsorbent quantity on simultaneous sorption of $\mathrm{MB}$ and $\mathrm{CV}$}

Adsorbent quantity is a key parameter that significantly effects on the adsorption efficiency by changing the biosorption capacity of the prepared sorbents [48]. Therefore, the impact of adsorbent quantity on MB and CV adsorption by OP, NOP and SNOP was determined in the range of 0.05$0.40 \mathrm{~g} / 100 \mathrm{~mL}$ of aqueous solution of $\mathrm{MB}$ and $\mathrm{CV}$ and the obtained data are displayed in Fig. 3. The removal percent of each dye increased by increasing the amount of sorbents which may be due to the fact that, by increasing the quantity of biosorbents, the number of sorbents active sites are increased which leads to the elimination of MB and CV [49]. Higher removal of MB may be attributed to smaller chemical structure of $\mathrm{MB}$ and the lower initial concentration $\left(129.9 \mathrm{mg} . \mathrm{L}^{-1}\right)$ of it as compared to the initial concentration of CV (152.9 mg. $\left.\mathrm{L}^{-1}\right)$.

It has been discovered that after adding more than $0.30 \mathrm{~g}$ of OP and $0.25 \mathrm{~g}$ of NOP and SNOP, no remarkable changes have been observed in the removal efficiency of dyes. Thus, these amounts of biosorbents were chosen as optimum dose for further experiments. 

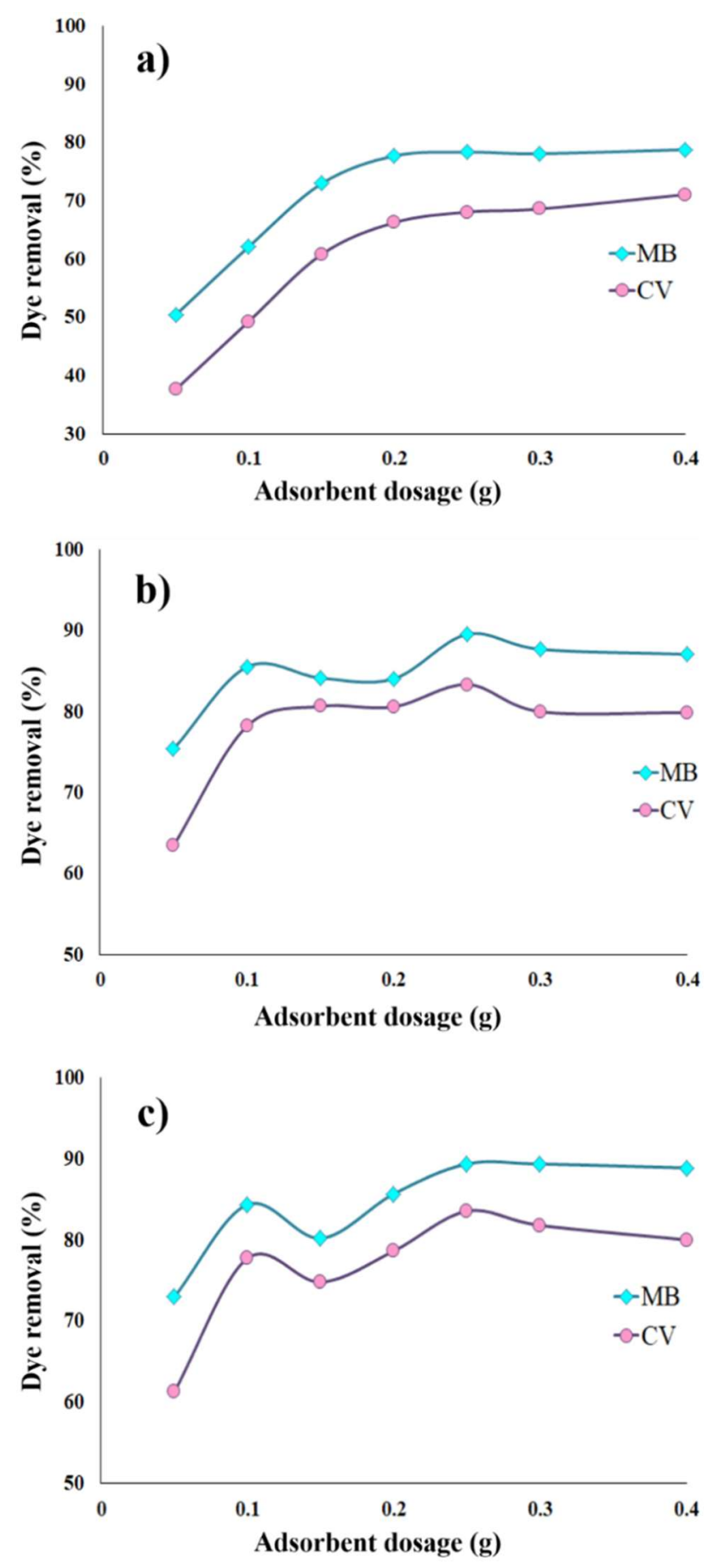

Fig. 3. Effect of adsorbent dosage on simultaneous removal of MB and CV by a) OP, b) NOP and c) SNOP 


\subsection{Effect of initial concentration and contact time on simultaneous sorption of $M B$ and}

\section{CV}

The results of the initial concentration effect of MB (52-172 mg. $\left.\mathrm{L}^{-1}\right)$ and CV (71-227 mg. $\left.\mathrm{L}^{-1}\right)$ on the competitive adsorption of these dyes are shown in Fig. 4. It was found that the quantity of MB and $\mathrm{CV}$ adsorbed on the sorbents was fast for the first 6 mins and after that it proceed with a lower rate (6- 20 mins) and after a while reached saturation. It was apparent from Fig. 6, that by increasing the initial dye concentration, the percentage of dye removal reduced which may be due to the saturation of adsorption sites on the adsorbent surface [3]. Moreover, there is an increase in adsorption percent which may be due to an enlargement of the mass transfer driving force, therefore, resulting in more $\mathrm{MB}$ and $\mathrm{CV}$ adsorption [50]. In addition, contact time has an effective role in adsorption processes. It is specified that the required contact time to reach adsorption equilibrium was 20 mins (Fig. 4). This quick elimination of dyes demonstrates that the binding sites of the prepared biosorbents were controlled by diffusion mechanism [51]. However, the experiments were performed at 40 mins to be certain that complete adsorption equilibrium was achieved. 
$\mathbf{A}$
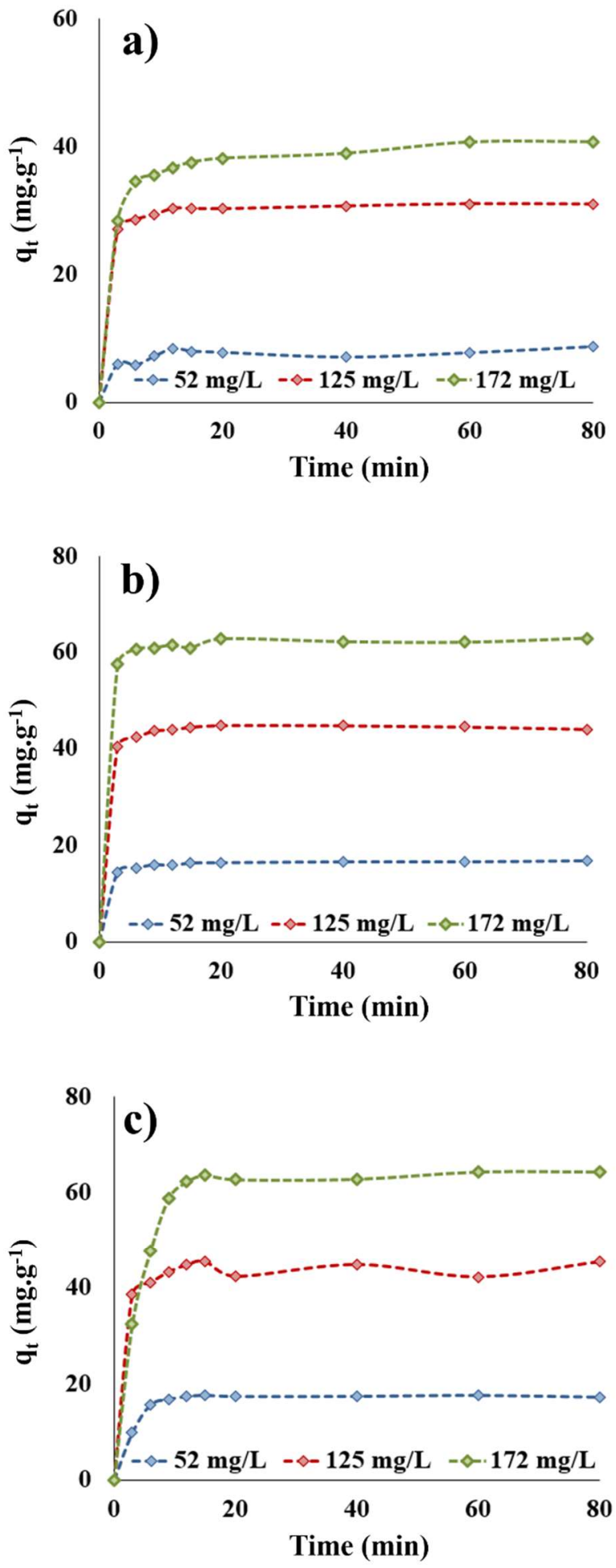

B
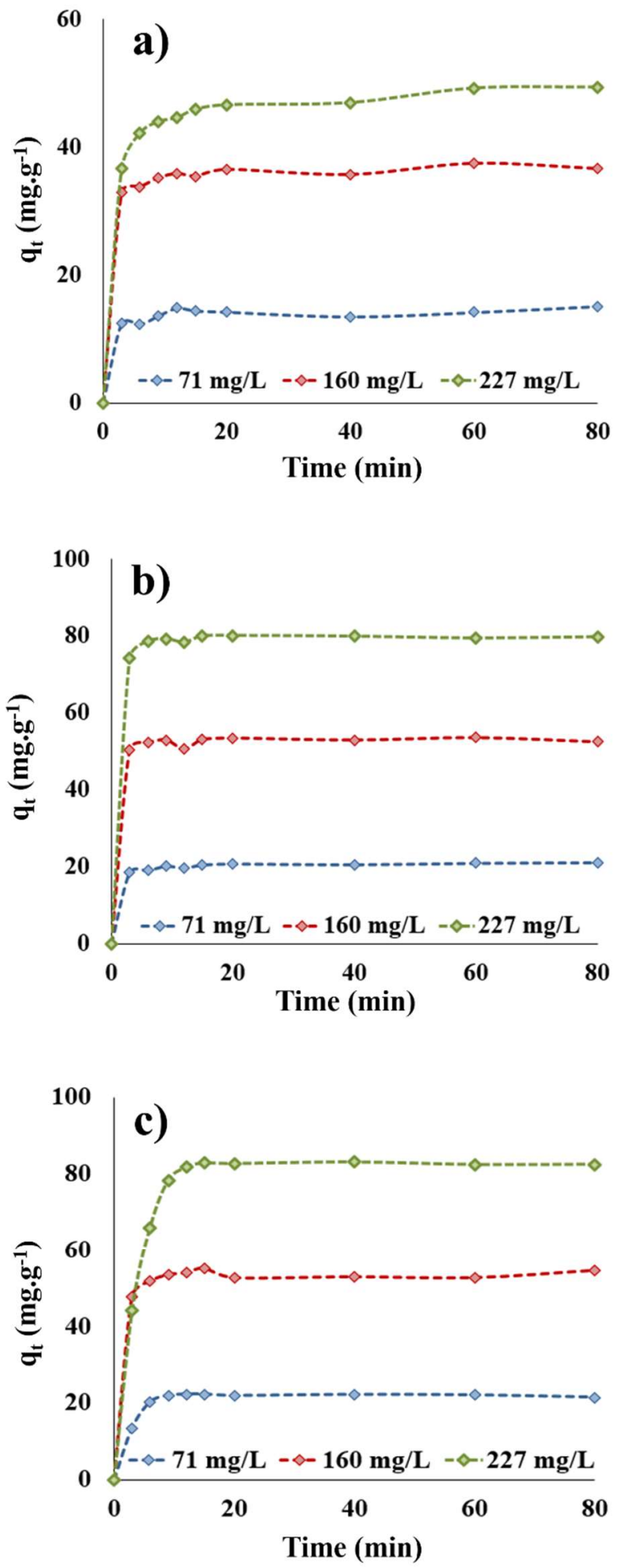

Fig. 4. Effect of contact time and initial concentration on the binary adsorption of A) MB and B) CV onto a) OP, b) NOP and c) SNOP 


\subsection{Effect of temperature on simultaneous adsorption of $\mathrm{MB}$ and $\mathrm{CV}$}

The effect of temperature on the adsorption was investigated at various temperatures $(30,40$ and $50{ }^{\circ} \mathrm{C}$ ). For this reason, different initial concentrations of $\mathrm{MB}$ within 21.47- 366.87 mg.L $\mathrm{L}^{-1}$ and different initial concentrations of $\mathrm{CV}$ within 28.99-456.32 mg. $\mathrm{L}^{-1}$ were provided. These equilibrium experiments were accomplished at optimum $\mathrm{pH}$ of 7 for all the used adsorbents, optimum dose of $0.30 \mathrm{~g}$ for OP and $0.25 \mathrm{~g}$ for NOP and SNOP and agitation time of 20 mins. Regarding to Fig. S3, it can be concluded that temperature has no significant influence on equilibrium capacities of simultaneous sorption of $\mathrm{MB}$ and $\mathrm{CV}$. It will be discussed in section 3.10 .

\subsection{Mechanism of simultaneous adsorption of MB and CV dyes onto SNOP}

Fig. 5 is a schematic of the surface treatment and proposed mechanism of simultaneous adsorption of MB and CV onto SNOP. Generally, surfactant molecules form monolayer namely hemimicelles on the surface of oxides. In this structure, the surfactant head group facing toward the hydrocarbon tail groups and its surface into solution. A new hydrophobic interaction between hydrocarbons tail groups form if the concentration of surfactant molecules present in the solution is higher, which causes the formation of separated surface aggregates which is called admicelles. The regions on the surface of oxides where these hemimicelle or admicelle are formed have potential to adsorb different contaminants [52]. Other possible mechanism is that the hydrocarbon tails group of surfactants may have interaction with the surface of adsorbent via hydrophobic bonding and the head group intended for the bulk of the solution, therefore, the surface has positive or negative charge. In this work, the head group of SDS molecules with negative charge toward the bulk of the solution and the alkyl tail of SDS might interact with NOP surface via hydrophobic bonding, thus, the surface has negative charge. It is concluded that the surface of SNOP is negative and the mechanism of binary adsorption of MB and CV dyes onto SNOP may be due to ionexchange or electrostatic interaction. Moreover, some of dyes molecules adsorbed onto SNOP surface via hydrophobic interaction between $\mathrm{MB}$ and $\mathrm{CV}$ molecules and hydrocarbon tail of surfactant (Fig. 5). 


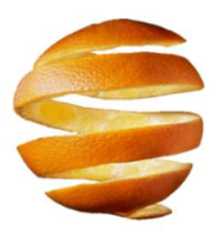

Orange peel (OP)

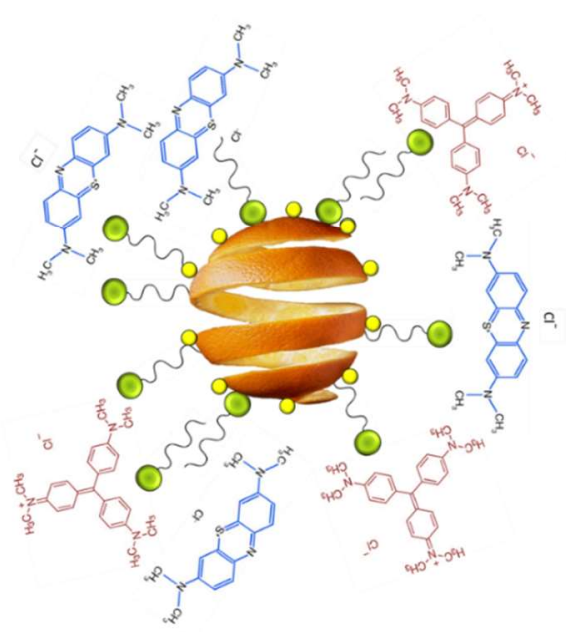

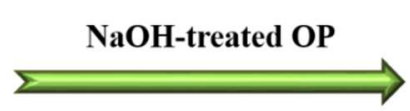

Active sites

Methylene blue
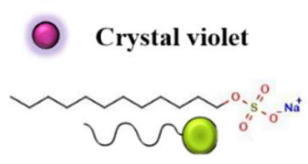

Sodium dodecyl sulfate (SDS)

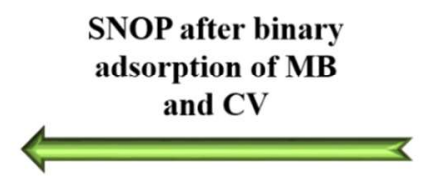

Fig. 5. Schematic illustration of the proposed mechanisms for simultaneous adsorption of MB and $\mathrm{CV}$ onto NOP and SNOP.

\subsection{Adsorption kinetic models in binary dyes system}

The dynamics of adsorption data was determined to figure out the kinetics of adsorption process $[53,54]$. In this work, the pseudo-first-order and pseudo-second-order kinetic models were used to obtain the equilibrium adsorption capacity and rate constants of binary adsorption of MB and CV process. By plotting $\ln \left(\mathrm{q}_{\mathrm{e}}-\mathrm{q}_{\mathrm{t}}\right)$ versus $\mathrm{t}$, the values of pseudo-first-order rate constants, $\mathrm{k}_{1}$ and $\mathrm{q}_{\mathrm{e}}$ can be determined from slope and intercept of the plots (Fig. S4). The obtained values and correlation coefficients $\left(\mathrm{R}^{2}\right)$ are shown in Table 2. The $\mathrm{R}^{2}$ reported for the pseudo-first-order kinetic model is in the range of 0.7974-0.9830. Moreover, the experimental and theoretical adsorption capacities attained from this model differed broadly, thus, it can be established that the pseudo-first-order kinetic model cannot illustrate simultaneous removal of MB and CV dyes on 
the prepared samples well. On the other hand, the kinetic data displayed a desirable agreement with pseudo-second-order kinetic model. By plotting t/q against $t$, an excellent linearity can be observed (Fig. 6). Regarding to the Table 2, the obtained qe values show an agreement with experimental $\mathrm{q}_{\mathrm{e}}$ values and the $\mathrm{R}^{2}$ values of pseudo-second-order model were equal or close to 1 , which is higher than the $\mathrm{R}^{2}$ values obtained from the pseudo-first-order model. Thus, the adsorption kinetics could be more agreeably defined by pseudo-second-order kinetic model for simultaneous removal of $\mathrm{MB}$ and $\mathrm{CV}$ onto the prepared adsorbents. Better fit to the pseudosecond-order kinetic model proves that the adsorption mechanism relies on the adsorbent and adsorbate, and the rate restrictive step can be chemisorption including valance forces through exchange or sharing electrons [55,56]. In addition, the second-order rate constants were applied to compute initial sorption rate $(\mathrm{h})$ of simultaneous adsorption of $\mathrm{MB}$ and $\mathrm{CV}$ using following equation:

$h_{D}=k_{2, D} q_{e, D}^{2}$

The initial rate adsorption of each dye is increased by increasing of solution concentration (Table 2).

During the adsorption mechanism, the dyes species move toward the surface of the biosorbent. When equilibrium is reached, the movement of dyes species from the solution reaches the maximum amount, therefore, measuring the quantity of the distribution of dyes species between the solution and the adsorbent is possible and the efficiency of the used adsorbents can be measured. After contacting a solid biosorbent with dyes-containing solutions, in the beginning, the dyes move to the surface of the liquid film from the bulk solution. This surface applies a very or less remarkable diffusion barrier [57]. The association of a remarkable quantum of diffusion barrier shows the principal role continued by the film diffusion during the adsorption process. In addition, the rate of sorption is limited by internal diffusion or external diffusion or by both of them. Internal diffusion controls the transferring of dyes species from the external surface to the internal surface of pores in the biosorbent. External diffusion controls the movement of the dyes species from the solution to the boundary layer of the liquid phase [58]. It is considered that during the biosorption of dyes onto a porous sorbent, three sequential steps are happened $[59,60]$ :

1. Transportation of dyes molecules over the liquid film surrounding the sorbent particles (film diffusion).

2. Adsorption of dyes species onto the pores of the sorbent (particle diffusion). 
3. Internal diffusion of ingoing dyes species by surface diffusion, pore diffusion, or both. Among these processes, third one cannot be considered as the rate-limiting step in the removal of contaminants because it occurs rapidly. Three possibilities exist about the other two steps:

a. If internal transport $<$ External transport, rate is directed by particle diffusion.

b. If internal transport $>$ External transport, rate is directed by film diffusion.

c. If internal transport $=$ External transport, the movement of the dyes species to the boundary is taken place. In this situation, the rate is not that much significant and afterward a liquid film surrounded by dyes molecules, with an appropriate concentration gradient, would be formed.

The Boyd model was applied additionally for analyzing the kinetic data to investigate the real slow step of the biosorption mechanism. This model can be expressed as below [61]:

$B_{t, D}=-0.4977-\ln (1-F)$

Where $\mathrm{F}$ exhibits the portion of dyes adsorbed at any time, $\mathrm{t}(\mathrm{min})$, which is obtained using Eq. (11):

$F=\frac{q_{t, D}}{q_{e, D}}$

Where $\mathrm{q}_{\mathrm{t}}$ and $\mathrm{q}_{\mathrm{e}}$ are the quantities of dyes removed after time $\mathrm{t}$ and infinite time ( 80 mins), respectively.

As shown in Fig. S5, $\mathrm{B}_{\mathrm{t}}$ values are plotted against time for the used sorbents in this study. These plots distinguish between the particle and film diffusion-controlled rates of adsorption. The linear lines of each dye for all concentrations did not go through the origin and the points were scattered. Therefore, it can be concluded that the simultaneous adsorption of MB and CV on all used biosorbents was principally controlled by external mass transport where particle diffusion was the rate-controlling step [62]. 
Table 2. Kinetic parameters for the simultaneous adsorption of MB and CV onto the prepared sorbents based on the Lagergren rate equation

Pseudo- $1^{\text {st }}$ order kinetic model

\begin{tabular}{|c|c|c|c|c|c|c|c|c|c|c|}
\hline \multirow{2}{*}{ Sorbent } & \multicolumn{2}{|c|}{$\mathrm{C}_{0}\left(\mathrm{mg} \cdot \mathrm{L}^{-1}\right)$} & \multicolumn{2}{|c|}{$\mathrm{q}^{\exp }\left(\mathrm{mg} \cdot \mathrm{g}^{-1}\right)$} & \multicolumn{2}{|c|}{$\mathrm{K}_{1}\left(1 . \mathrm{min}^{-1}\right)$} & \multicolumn{2}{|c|}{$\mathrm{q}_{\mathrm{e}}^{\mathrm{Cal}}\left(\mathrm{mg} \cdot \mathrm{g}^{-1}\right)$} & \multicolumn{2}{|c|}{$\mathrm{R}^{2}$} \\
\hline & MB & $\mathrm{CV}$ & MB & $\mathrm{CV}$ & MB & $\mathrm{CV}$ & MB & $\mathrm{CV}$ & MB & $\mathrm{CV}$ \\
\hline \multirow{3}{*}{$\mathrm{OP}$} & 52.20 & 71.55 & 8.6556 & 15.1000 & 0.1253 & 0.1111 & 6.897 & 5.682 & 0.8296 & 0.8023 \\
\hline & 125.65 & 159.63 & 31.0337 & 37.4014 & 0.1059 & 0.0869 & 4.321 & 5.604 & 0.7974 & 0.9064 \\
\hline & 171.83 & 226.96 & 38.9000 & 46.9100 & 0.1472 & 0.1927 & 13.125 & 17.734 & 0.9765 & 0.9830 \\
\hline \multirow{3}{*}{ NOP } & 52.20 & 71.55 & 16.5418 & 20.8073 & 0.1493 & 0.1490 & 3.044 & 4.224 & 0.9116 & 0.9013 \\
\hline & 125.65 & 159.63 & 44.8000 & 53.4321 & 0.3125 & 0.1781 & 18.112 & 4.530 & 0.8918 & 0.9154 \\
\hline & 171.83 & 226.96 & 62.8000 & 79.9000 & 0.2209 & 0.3540 & 11.922 & 21.948 & 0.9385 & 0.8659 \\
\hline \multirow{3}{*}{ SNOP } & 52.20 & 71.55 & 17.9000 & 22.2500 & 0.1043 & 0.1490 & 2.778 & 4.224 & 0.8971 & 0.9013 \\
\hline & 125.65 & 159.63 & 45.6000 & 55.1000 & 0.3125 & 0.1781 & 18.112 & 4.530 & 0.8918 & 0.9154 \\
\hline & 171.83 & 226.96 & 64.3600 & 83.0000 & 0.2209 & 0.3540 & 11.922 & 21.948 & 0.9385 & 0.8659 \\
\hline
\end{tabular}

Pseudo- $2^{\text {nd }}$ order kinetic model

\begin{tabular}{|c|c|c|c|c|c|c|c|c|c|c|}
\hline \multirow{2}{*}{ Sorbent } & \multicolumn{2}{|c|}{$\mathrm{C}_{0}\left(\mathrm{mg} \cdot \mathrm{L}^{-1}\right)$} & \multicolumn{2}{|c|}{$\mathrm{h}\left(\mathrm{mg} \cdot \mathrm{g}^{-1} \cdot \mathrm{min}^{-1}\right)$} & \multicolumn{2}{|c|}{$\mathrm{K}_{2}\left(\mathrm{~g} \cdot \mathrm{mg}^{-1} \cdot \mathrm{min}^{-1}\right)$} & \multicolumn{2}{|c|}{$\mathrm{q}_{\mathrm{e}}^{\mathrm{Cal}}\left(\mathrm{mg} \cdot \mathrm{g}^{-1}\right)$} & \multicolumn{2}{|c|}{$\mathrm{R}^{2}$} \\
\hline & MB & $\mathrm{CV}$ & MB & $\mathrm{CV}$ & MB & $\mathrm{CV}$ & $\mathrm{MB}$ & $\mathrm{CV}$ & $\mathrm{MB}$ & $\mathrm{CV}$ \\
\hline \multirow{3}{*}{ OP } & 52.20 & 71.55 & 33.777 & 13.891 & 0.0405 & 0.0596 & 9.132 & 15.267 & 0.9419 & 0.9899 \\
\hline & 125.65 & 159.63 & 67.563 & 74.660 & 0.0700 & 0.0540 & 31.05 & 37.174 & 0.9998 & 0.9995 \\
\hline & 171.83 & 226.96 & 34.093 & 48.543 & 0.0208 & 0.0204 & 40.486 & 48.780 & 0.9998 & 0.9999 \\
\hline \multirow{3}{*}{ NOP } & 52.20 & 71.55 & 30.110 & 34.965 & 0.1066 & 0.0782 & 16.807 & 21.141 & 0.9996 & 0.9991 \\
\hline & 125.65 & 159.63 & 105.304 & 212.773 & 0.0505 & 0.0744 & 45.662 & 53.476 & 1.0000 & 0.9985 \\
\hline & 171.83 & 226.96 & 188.684 & 322.600 & 0.0471 & 0.0496 & 63.291 & 80.645 & 0.9995 & 0.9998 \\
\hline \multirow{3}{*}{ SNOP } & 52.20 & 71.55 & 30.120 & 34.965 & 0.1066 & 0.0782 & 16.807 & 21.141 & 0.9996 & 0.9991 \\
\hline & 125.65 & 159.63 & 105.304 & 212.770 & 0.0505 & 0.0744 & 45.662 & 53.476 & 1.0000 & 0.9985 \\
\hline & 171.83 & 226.96 & 188.684 & 322.580 & 0.0471 & 0.0496 & 63.291 & 80.645 & 0.9995 & 0.9998 \\
\hline
\end{tabular}



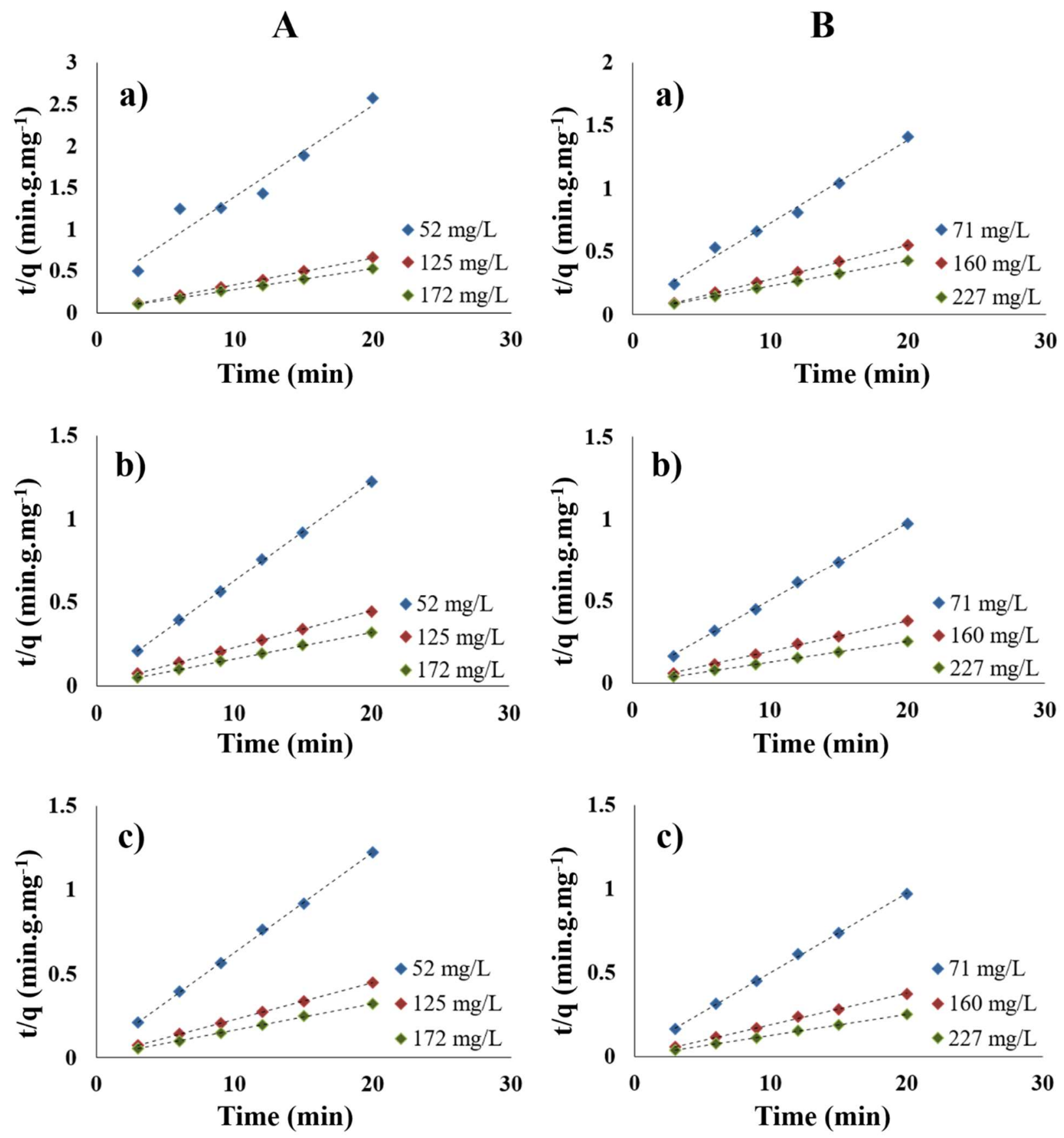

Fig. 6. Pseudo-second-order kinetic model for binary adsorption of A) MB and B) CV onto a)

$$
\mathrm{OP}, \mathrm{b}) \mathrm{NOP} \text { and c) SNOP. }
$$

\subsection{Adsorption thermodynamics}

Thermodynanic parameters like standard enthalpy $\left(\Delta \mathrm{H}^{\circ}\right)$, Gibbs free energy $\left(\Delta \mathrm{G}^{\circ}\right)$ and entropy $\left(\Delta \mathrm{S}^{\circ}\right)$ of adsorption express the type and nature of adsorption and disarrangement of the system at 


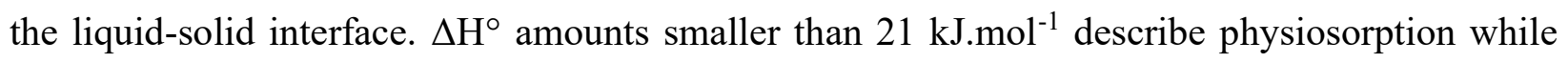
greater than this value show chemisorption. If $\Delta \mathrm{G}^{\circ}$ is negative, adsorption processes takes place spontaneously [63]. The negative values of $\Delta \mathrm{S}^{\circ}$ demonstrate disorder decreasing at the interface during sorption mechanism. Using following equations, the thermodynamic parameters of $\Delta \mathrm{H}^{\circ}$, $\Delta \mathrm{G}^{\circ}$ and $\Delta S^{\circ}$ can be calculated $[64,65]$ :

$\Delta \mathrm{G}^{0}=-R T \ln K_{D}$

Where $\mathrm{K}_{\mathrm{D}}$ is the distribution coefficient and is attained by following equation:

$K_{D}=\frac{q_{e, D}}{C_{e, D}}$

$\ln K_{D}=\frac{-\Delta H^{0}}{R T}+\frac{\Delta G^{0}}{R}$

Where, $\mathrm{R}$ represents universal gas constant $\left(8.314 \mathrm{~J} \cdot \mathrm{mol}^{-1} \cdot \mathrm{K}^{-1}\right)$ and $\mathrm{T}$ is the absolute temperature in $\mathrm{K}$. The plots of $\ln \mathrm{K}_{\mathrm{D}}$ were found to be linear. The values of $\Delta \mathrm{H}^{\circ}$ and $\Delta S^{\circ}$ were obtained from the slope and intercept of the plots, respectively. As shown in Table 3, the values of $\Delta \mathrm{H}^{\circ}$ were negative which expresses that the adsorption reaction is exothermic in nature. Furthermore, the negative values of $\Delta G^{\circ}$ prove that simultaneous adsorption of $\mathrm{MB}$ and $\mathrm{CV}$ onto the prepared sorbents for both dyes is spontaneous in nature and the process is feasible. The values of $\Delta G^{\circ}$ in the range of 1 to $-20 \mathrm{~kJ} \mathrm{~mol}^{-1}$ represent physical sorption, although higher $\Delta G^{\circ}$ are characteristics for chemical adsorption, which generally falls into the range of -80 to $-400 \mathrm{~kJ}^{-\mathrm{mol}^{-1}}$ [66]. The positive values of $\Delta S^{\circ}$ for both $\mathrm{MB}$ and $\mathrm{CV}$, in binary sorption system, onto OP and for adsorption of MB onto NOP, indicates that the freedom of the dyes is not much limited in OP or NOP approving a physical biosorption, which is proved by the approximately low values of $\Delta \mathrm{G}^{\circ}$. Furthermore, these positive values exhibit increased randomness at solid-liquid interface, proving the accumulation of dye(s). Reversely, the values of $\Delta S^{\circ}$ for adsorption of CV onto NOP and for adsorption of both dyes onto SNOP was negative which is indicative of absence of a considerable change in the internal structure of NOP and SNOP through the adsorption process, the formation of stable chemical complexes on the sorbents surface and the association of dye(s) molecules with NOP or SNOP active sites [67]. The activation energy $\left(E_{a}\right)$ can be attained from the slope of plot $\ln (1-\theta)$ against $1 /$ T. $\theta$ is the surface coverage which can be obtained from the equation below $[64,68]$ :

$\theta=1-\frac{C_{D}}{C_{0, D}}$ 
Where $\mathrm{C}_{0}, \mathrm{D}$ is the initial concentration and $\mathrm{C}_{\mathrm{D}}$ is the residual concentration of each dye in the solution $\left(\mathrm{mg} \cdot \mathrm{L}^{-1}\right)$.

The values of sticking probability $\left(\mathrm{S}^{*}\right)$ was calculated from the experimental data in order to support the declaration that physical adsorption is the controlling mechanism. It was determined by following equation which is a modified Arrhenius type equation [64,69]:

$$
S^{*}=(1-\theta) e^{\frac{-E a}{R T}}
$$

The potential of dyes to remain continuously on the sorbent surface is demonstrated by the parameter $\mathrm{S}^{*}$ which is reported in Table 3. The impact of temperature on the $\mathrm{S}^{*}$ was calculated over the temperature range from $303-323 \mathrm{~K}$ by evaluating the surface coverage at different temperatures. The sticking probability $\left(\mathrm{S}^{*}\right)$ and the activation energy $\left(\mathrm{E}_{\mathrm{a}}\right)$ are determined from the plot with an acceptable fit for binary adsorption of $\mathrm{MB}$ and $\mathrm{CV}$ on the prepared sorbents. The values of $E_{a}$ specify the type of adsorption. Low activation energies $\left(E_{a}<40 \mathrm{~kJ} . \mathrm{mol}^{-1}\right)$ represent physical sorption, although higher activation energies $\left(E_{a}>40 \mathrm{~kJ} \cdot \mathrm{mol}^{-1}\right)$ are characteristics for chemical adsorption. The given values of $\mathrm{E}_{\mathrm{a}}$ in Table 3 represent better simultaneous adsorption of $\mathrm{MB}$ and $\mathrm{CV}$ onto prepared samples; therefore, it can be concluded that the sorption mechanism is exothermic and diffusion controlled. As shown in Table 3, the probability of simultaneous MB and CV sticking to the OP, NOP and SNOP surface is $0<\mathrm{S}^{*}<1$ for MB and CV which approved that the sorption process is physiosorption $[48,69]$. The negative values of the activation energy (Table 3) suggested that the rise in the solution temperature did not favor MB and CV adsorption onto OP and NOP. The negative value also indicates an exothermic reaction and the low values of the activation energy indicate that the dyes adsorption onto OP and NOP might be physisorption. It means that the rate-limiting step of dyes adsorption onto these sorbents involved predominantly a physical process [70]. 
Table 3. Thermodynamic parameters for the binary adsorption of $\mathrm{MB}$ and $\mathrm{CV}$ onto the prepared sorbents.

\begin{tabular}{|c|c|c|c|c|c|c|c|c|c|c|c|}
\hline \multirow[t]{2}{*}{ Sorbent } & \multirow{2}{*}{$\begin{array}{c}\text { Temperature } \\
\text { (K) }\end{array}$} & \multicolumn{2}{|c|}{$\begin{array}{c}\Delta \mathrm{G}^{\circ} \\
\left(\mathrm{kJ} \cdot \mathrm{mol}^{-1}\right)\end{array}$} & \multicolumn{2}{|c|}{$\begin{array}{c}\Delta \mathrm{H}^{\circ} \\
\left(\mathrm{kJ} \cdot \mathrm{mol}^{-1}\right)\end{array}$} & \multicolumn{2}{|c|}{$\begin{array}{c}\Delta \mathrm{S}^{\circ} \\
\left(\mathrm{J} \cdot \mathrm{mol}^{-1} \cdot \mathrm{K}^{-1}\right)\end{array}$} & \multicolumn{2}{|c|}{$\begin{array}{c}\mathrm{E}_{\mathrm{a}} \\
\left(\mathrm{kJ} \cdot \mathrm{mol}^{-1}\right)\end{array}$} & \multicolumn{2}{|c|}{$\mathrm{S}^{*}$} \\
\hline & & MB & $\mathrm{CV}$ & MB & $\mathrm{CV}$ & MB & $\mathrm{CV}$ & MB & $\mathrm{CV}$ & $\mathrm{MB}$ & $\mathrm{CV}$ \\
\hline \multirow{3}{*}{$\mathrm{OP}$} & 303 & -2.274 & -1.794 & & & & & & & 0.378 & 0.430 \\
\hline & 313 & -2.359 & -1.739 & -0.148 & -1.265 & 7.01 & 1.51 & -0.011 & -0.086 & 0.377 & 0.434 \\
\hline & 323 & -2.414 & -1.755 & & & & & & & 0.379 & 0.438 \\
\hline \multirow{3}{*}{ NOP } & 303 & -4.674 & -3.853 & & & & & & & 0.163 & 0.213 \\
\hline & 313 & -4.812 & -3.952 & -2.185 & -5.026 & 8.27 & -3.73 & -0.219 & -0.469 & 0.164 & 0.215 \\
\hline & 323 & -4.836 & -3.771 & & & & & & & 0.171 & 0.235 \\
\hline \multirow{3}{*}{ SNOP } & 303 & -3.551 & -2.984 & & & & & & & 0.234 & 0.276 \\
\hline & 313 & -4.808 & -4.297 & -12.796 & -13.196 & -26.07 & -28.62 & 0.696 & 1.012 & 0.164 & 0.193 \\
\hline & 323 & -4.276 & -3.918 & & & & & & & 0.202 & 0.225 \\
\hline
\end{tabular}

\subsection{Desorption and regeneration studies}

Desorption study clarifies the mechanism of sorption process. In order to restore the primary capacity of adsorption, regeneration of the used biosorbents is essential. If the adsorbed dyes onto the biosorbents could be desorbed by water, it can be concluded that the biosorption is taken place by weak bonds. If the desorption of dyes could be happened by strong acids like $\mathrm{HCl}$, it would be stated that dyes attach onto the biosorbents by electrostatic attraction or ion exchange [71]. Therefore, the neutral distilled water and $\mathrm{HCl}\left(0.1\right.$ mol. $\left.\mathrm{L}^{-1}\right)$ aqueous solution were used for desorption experiments. For this reason, the adsorption experiments were done by using the optimum dose of each biosorbent in $100 \mathrm{~mL}$ of $\mathrm{MB}$ and $\mathrm{CV}$ multicomponent solution with initial concentration of 100 and $125 \mathrm{mg} . \mathrm{L}^{-1}$, respectively. Table 4 demonstrates the results of desorption assays using dyes-loaded orange peels. The approximately high desorption amounts of MB and $\mathrm{CV}$ in $\mathrm{HCl}$ solution recommend that adsorption of the dyes was performed mainly via ion exchange or electrostatic attraction. In addition, the results proved that the sorbents could be regenerated and reused after binary adsorption of $\mathrm{MB}$ and $\mathrm{CV}$. 
Table 4. Desorption percent of $\mathrm{MB}$ and $\mathrm{CV}$ in water and $\mathrm{HCl}$

\begin{tabular}{cccccccc}
\hline & & \multicolumn{2}{c}{ \% Adsorption } & \% Des. in $\mathrm{H}_{2} \mathrm{O}$ & \multicolumn{2}{c}{ \% Des. in $\mathrm{HCl}$} \\
Sorbent & dose $(\mathrm{g})$ & \multicolumn{2}{c}{ \% } & & & \multicolumn{2}{c}{$\left(0.1 \mathrm{~mol}^{-1}\right)$} \\
& & $\mathrm{MB}$ & $\mathrm{CV}$ & $\mathrm{MB}$ & $\mathrm{CV}$ & $\mathrm{MB}$ & $\mathrm{CV}$ \\
\hline OP & 0.3 & 65.39 & 73.06 & 4.76 & 4.84 & 28.76 & 43.00 \\
NOP & 0.25 & 91.66 & 89.05 & 3.28 & 7.41 & 20.26 & 36.04 \\
SNOP & 0.25 & 95.34 & 94.07 & 1.93 & 4.11 & 18.87 & 32.84 \\
\hline
\end{tabular}

\subsection{Selective adsorption}

Due to the fact that dyes exist simultaneously in wastewaters and in order to study the performance of the used biosorbents in the industrial situation, the adsorption of ternary system methylene blue, crystal violet and methyl orange (MO) was checked out. The absorption visible spectrum of each solution is shown in Fig. 7. These experiments were performed at optimum $\mathrm{pH}$ value and thus the surface of sorbents was negatively-charged during the sorption process and the optimum dose of adsorbents was used. As shown in spectrum of each sorbent, it can be observed that each dye is adsorbed onto the biosorbents, although the sorption of $\mathrm{MO}$, an anionic dye, onto negatively charged surface sorbents was not expected due to the electrostatic repulsion. It may be attributed to the fact that the MB and CV dye molecules are adsorbed onto the sorbents, make the surface slightly positive and make the sorption of MO onto the sorbent possible. 


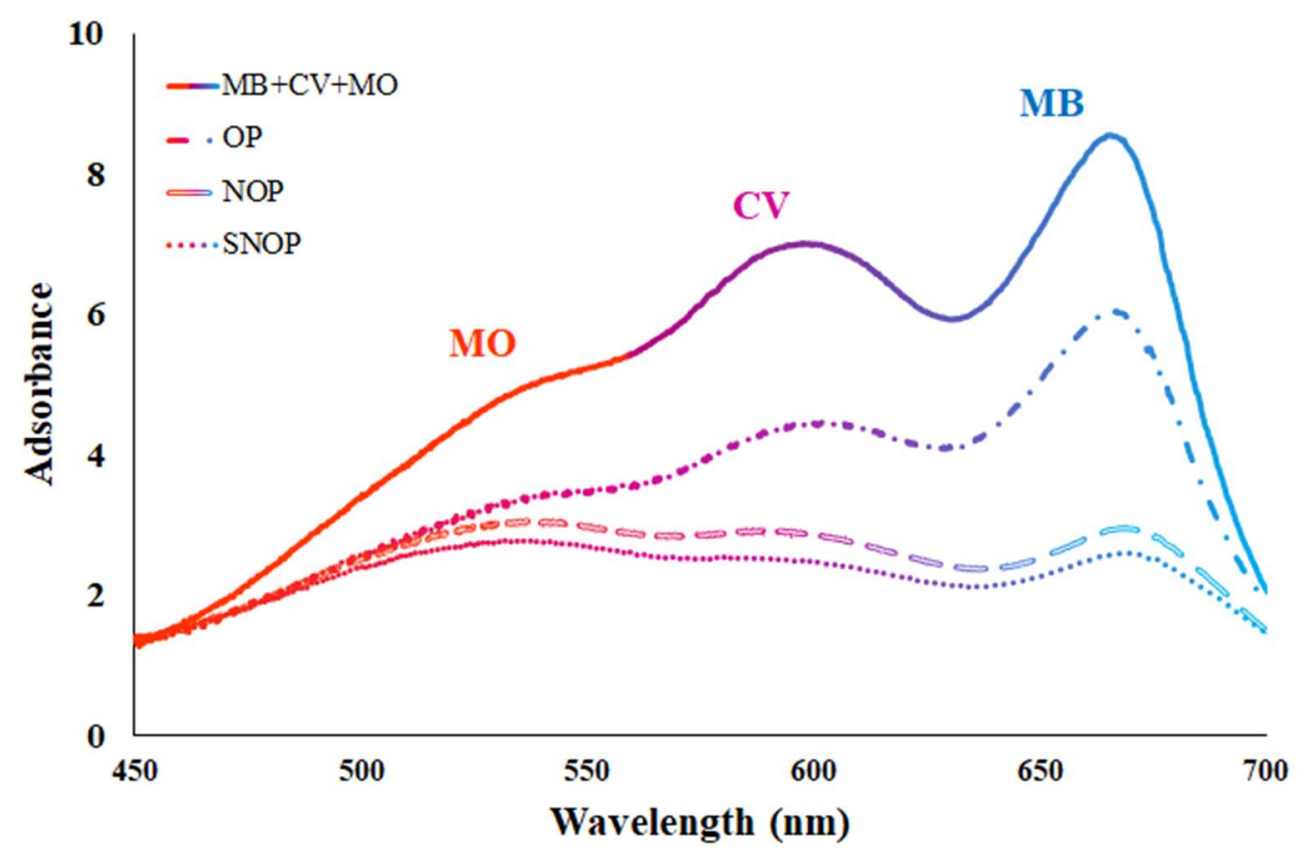

Fig. 7. Visible absorption spectra of the ternary solution containing $\mathrm{MB}, \mathrm{CV}$ and $\mathrm{MO}$ before and after adsorption.

\subsection{Artificial neural network (ANN) modeling}

Recently, ANN models have widely been used for simulation, optimization, forecasting and classification [35]. ANNs are organized based on uncomplicated models of human brain, like learning, thinking and problem solving. ANNs models, which contain weights and neurons, depend on the conjecture that a complicated relevance between dependent and independent variables could be learned by a system of simple processing elements [72,73]. Developing an ANN model consists of the following stages:

Selecting data and processing, choosing an appropriate structure for the neural network, training algorithm selection for the network and using the network for validation and simulation [74]. The ANN is typically organized in layers. It contains an input layer, one or more of hidden layers and an output layer. There are some simple processing elements in each layer which is called neurons. Neurons associate layers by weight adjust signals. Signals from external sources are received by the input layer. In this layer, each input is being weighted separately and the hidden layer receives these data in order to processing [75]. In hidden layers, the preprocessing is performed and using transfer functions and the results are transferred into output layer or other hidden layers [73]. A back propagation neural network, which is being used extensively has a 
powerful mathematical basis based on gradient descent learning [76]. Different factors such as training algorithm, number of hidden neurons and initial weights can influence in training modern deep neural networks and achieve favorable results [77]. Therefore, to optimizing these parameters, the experimental data of simultaneous adsorption of $\mathrm{MB}$ and $\mathrm{CV}$ were randomly divided into three groups in which $70 \%$ of 62 data of both dyes is used for training, $15 \%$ for testing and $15 \%$ for validating. In this work, a three-layer perceptron ANN with a back-propagation algorithm was established with tansig and purelin as the transfer functions at the hidden and the output layers, respectively (Fig. 8). The structure of ANN in this study for all biosorbents is 5-n-1 where $\mathrm{n}$ is the number of hidden neurons which is different for each dye and sorbent, 5 is the number of input neurons which are the effective parameters on adsorption process that include the solution $\mathrm{pH}$, adsorbent dose, initial concentration, contact time and temperature and number 1 indicates the desired output of the problem which in this study, it is the removal percentages of $\mathrm{MB}$ or $\mathrm{CV}$ at various situations. In order to reduce the errors, decline the training time and avoid any numerical overflow, normalizing all input and output variables between 0.1 and 0.9 will be helpful [78]:

$n_{i}=0.8 \frac{\left(x_{i}-m i\left(x_{i}\right)\right)}{\left(\max \left(x_{i}\right)-\min \left(x_{i}\right)\right)}+0.1$

Where $\mathrm{x}_{\mathrm{i}}$ is the original value and $\mathrm{n}_{\mathrm{i}}$ is the normalized value of $\mathrm{x}_{\mathrm{i}}$.

The mean square error (MSE) and the determination coefficient $\left(\mathrm{R}^{2}\right)$ measure the performance of the model according to the following equations [35]:

$M S E=\frac{1}{N} \sum_{i=1}^{N}\left(y_{p r d, i}-y_{\text {exp }, i}\right)^{2}$
$R^{2}=1-\frac{\sum_{i=1}^{N}\left(y_{p r d, i}-y_{\text {exp }, i}\right)^{2}}{\sum_{i=1}^{N}\left(y_{p r d, i}-y_{m}\right)^{2}}$

Where $\mathrm{N}$ is the number of all the training data, $\mathrm{y}_{\text {prd, }}$ is the predicted values, $\mathrm{y}_{\exp , \mathrm{i}}$ is the ith calculated value and $\mathrm{y}_{\mathrm{m}}$ is the mean value of $\mathrm{y}_{\mathrm{exp}, \mathrm{i}}$.

Lower MSE and higher $\mathrm{R}^{2}$ indicate a model with a very good prediction performance [35]. Optimization of the number of hidden neurons was performed after many repetitions. The optimal number of hidden neurons and MSE values of each dye is listed in Table 5. 
Garson recommended an equation based on the dividing of weights for evaluating the relative importance of each input variable:

$$
I_{j}=\frac{\sum_{m=1}^{m=N h}\left(\left(\frac{\left|W_{j m}^{i h}\right|}{\sum_{k=1}^{N i}\left|W_{k m}^{i h}\right|}\right) \times\left|W_{m n}^{h o}\right|\right)}{\sum_{k=1}^{k=N}\left\{\sum_{k=1}^{N i}\left(\frac{\left|W_{k m}^{i h}\right|}{\sum_{k=1}^{N i}\left|W_{k m}^{i h}\right|}\right) \times\left(\left|W_{m n}^{h o}\right|\right)\right\}}
$$

Where $I_{j}$ is the relative importance of the jth input variable on the output variable; $N_{h}$ and $N_{i}$ are the number of hidden and input neurons, respectively; W is connection weights; the subscripts k, $\mathrm{m}$ and $\mathrm{n}$ indicate input, hidden and output neurons, respectively; and superscripts $\mathrm{I}, \mathrm{h}$ and $\mathrm{o}$ indicate input, hidden and output layers, respectively [79]. Fig. 9 demonstrates the importance of each input variable on adsorption of $\mathrm{MB}$ and $\mathrm{CV}$, respectively. It can be observed that all variables have important influence on simultaneous adsorption of $\mathrm{MB}$ and $\mathrm{CV}$. Experimental and predicted values of dyes removal efficiency for all 62 data are compared and the results are shown in Fig. 10. The predicted values are found to be relatively similar to the experimental values. In addition, the performance of the designed model was evaluated by comparison of the experimental and predicted values in test data set. The results are presented in Fig. S6. Regarding to $\mathrm{R}^{2}$ values on the test data sets and based on Fig. S6 and Table 5, it is obvious that the ANN model is accurate for predicting and modeling the complex behavior of the multicomponent adsorption of dyes using modified OP.

Table 5. Number of neurons and MSE of the used ANN model

\begin{tabular}{ccccc}
\hline \multirow{2}{*}{ Sorbent } & \multicolumn{2}{c}{ Number of neurons in hidden layer } & \multicolumn{2}{c}{ MSE } \\
\cline { 2 - 5 } & MB & CV & MB & CV \\
\hline OP & 8 & 26 & 0.0014 & $9.71 \mathrm{e}-04$ \\
NOP & 19 & 9 & $4.03 \mathrm{e}-04$ & $6.77 \mathrm{e}-04$ \\
SNOP & 15 & 4 & $5.93 \mathrm{e}-04$ & $6.2 \mathrm{e}-04$ \\
\hline
\end{tabular}




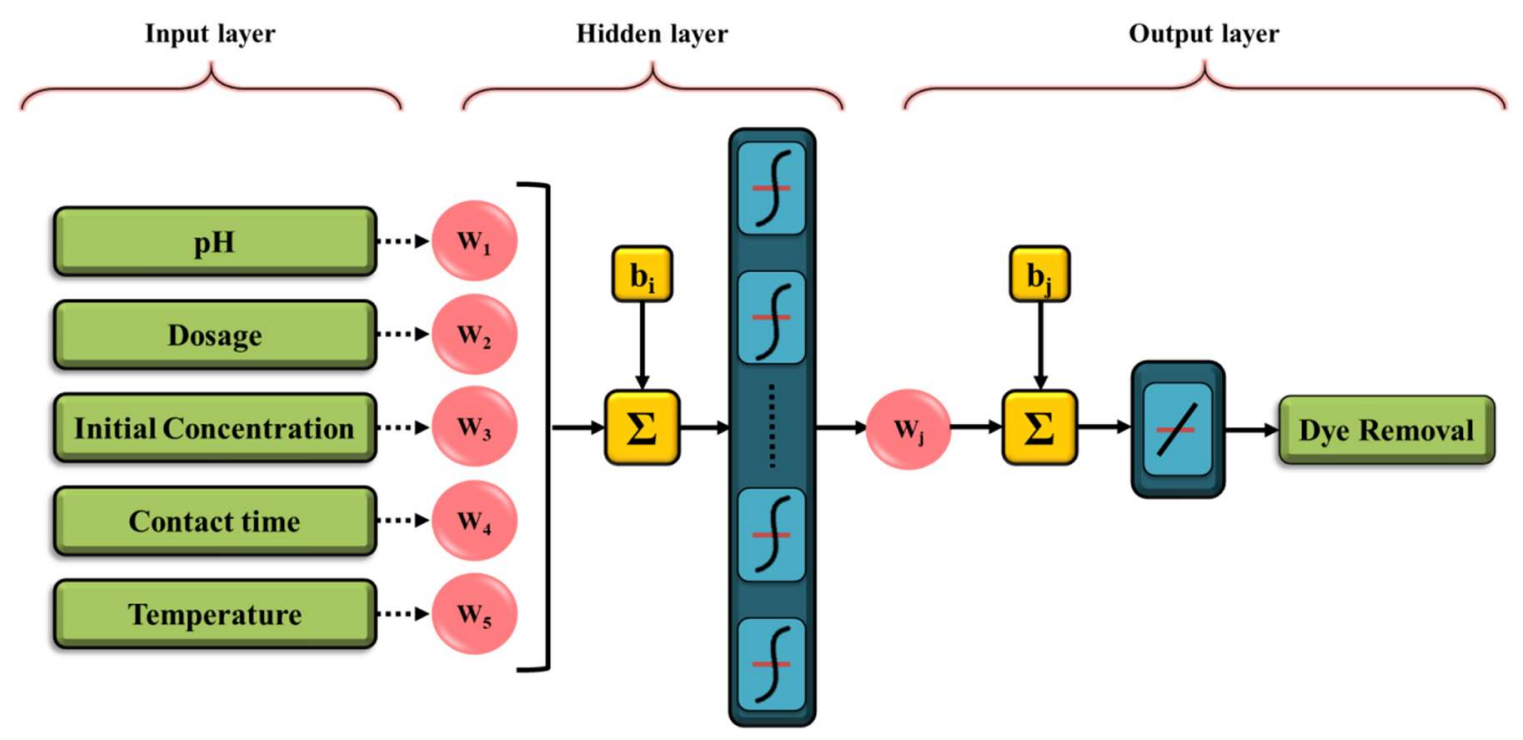

Fig. 8. Schematic diagram of the three layers ANN model with five input layers and one output layer. 
A
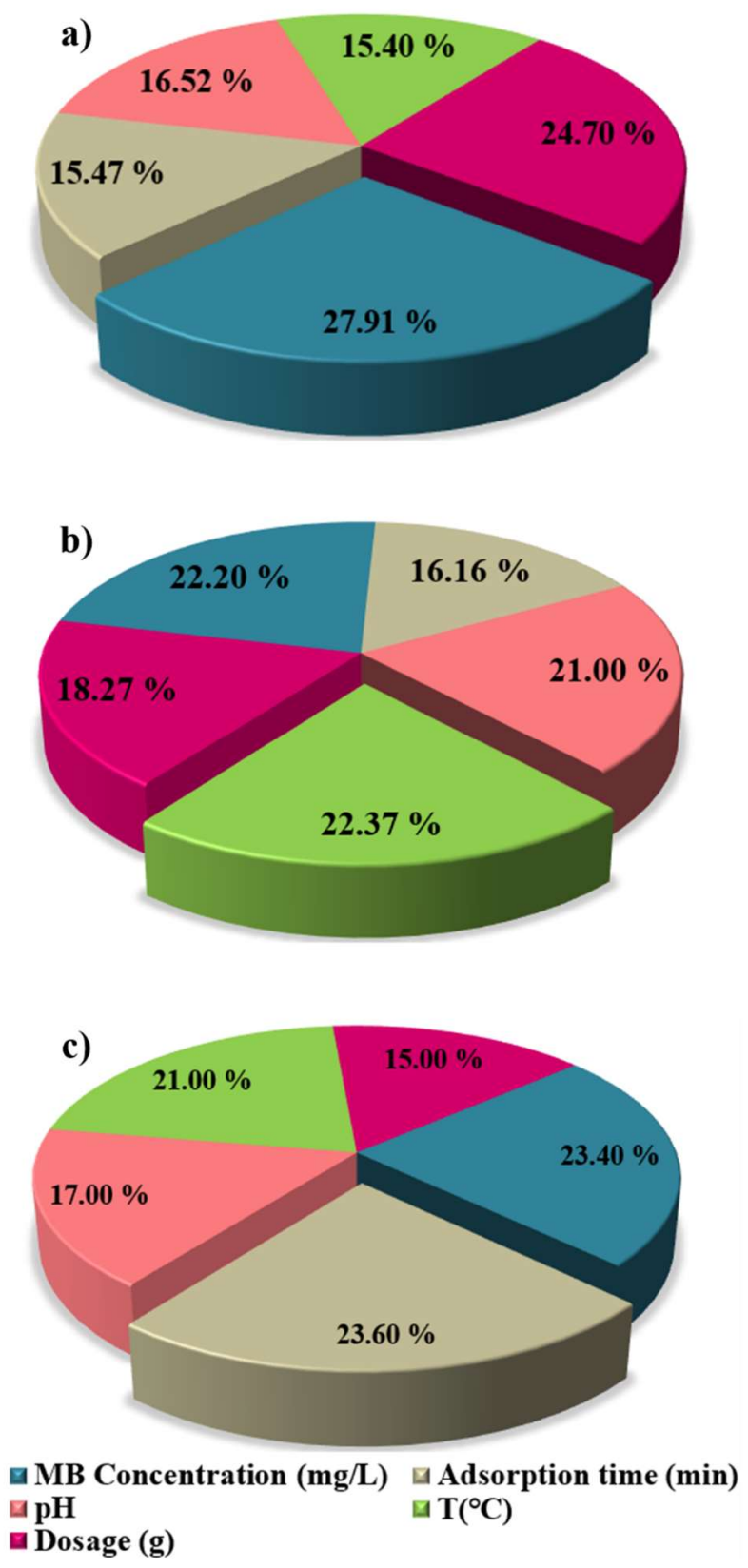
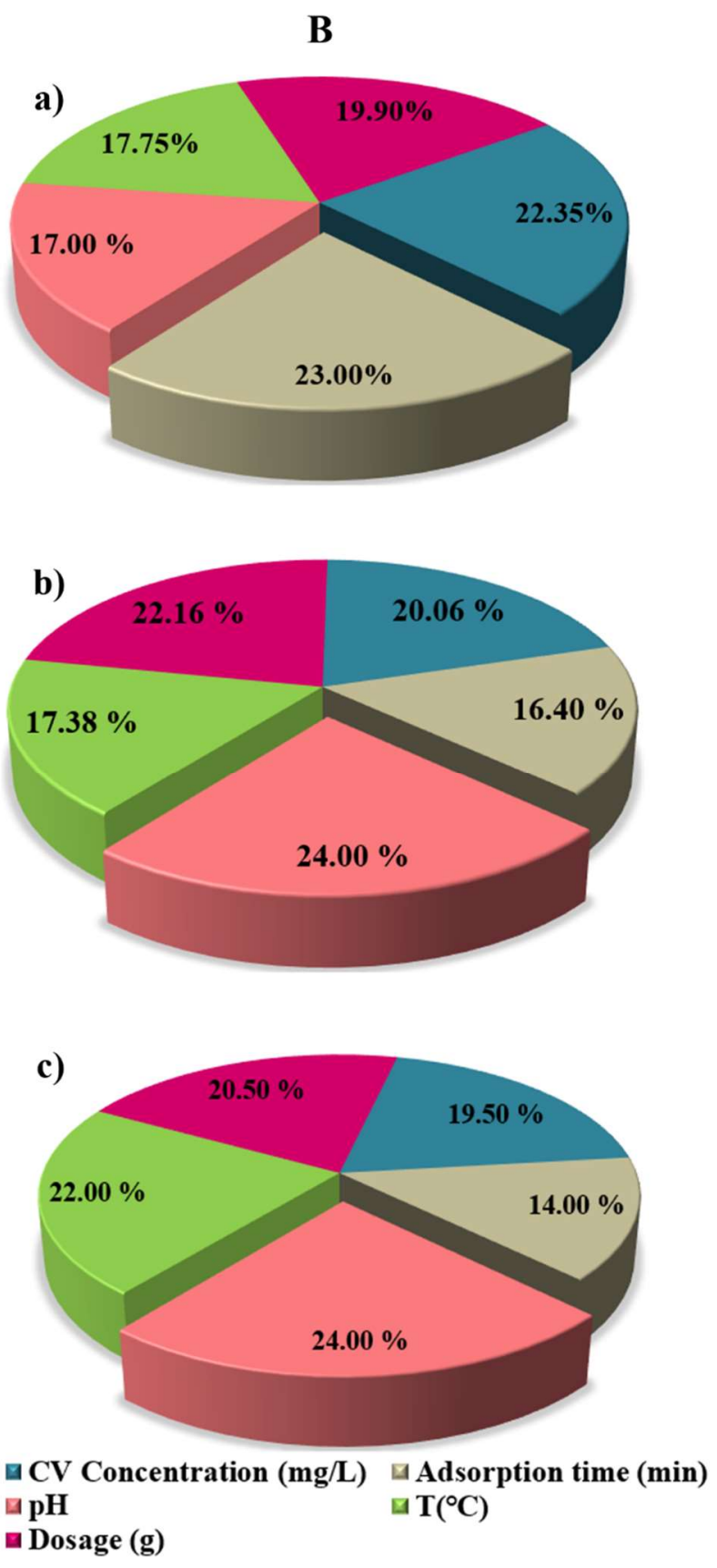

Fig 9. Relative importance of the input variables on binary adsorption of A) MB and B) CV onto a) OP, b) NOP and c) SNOP 

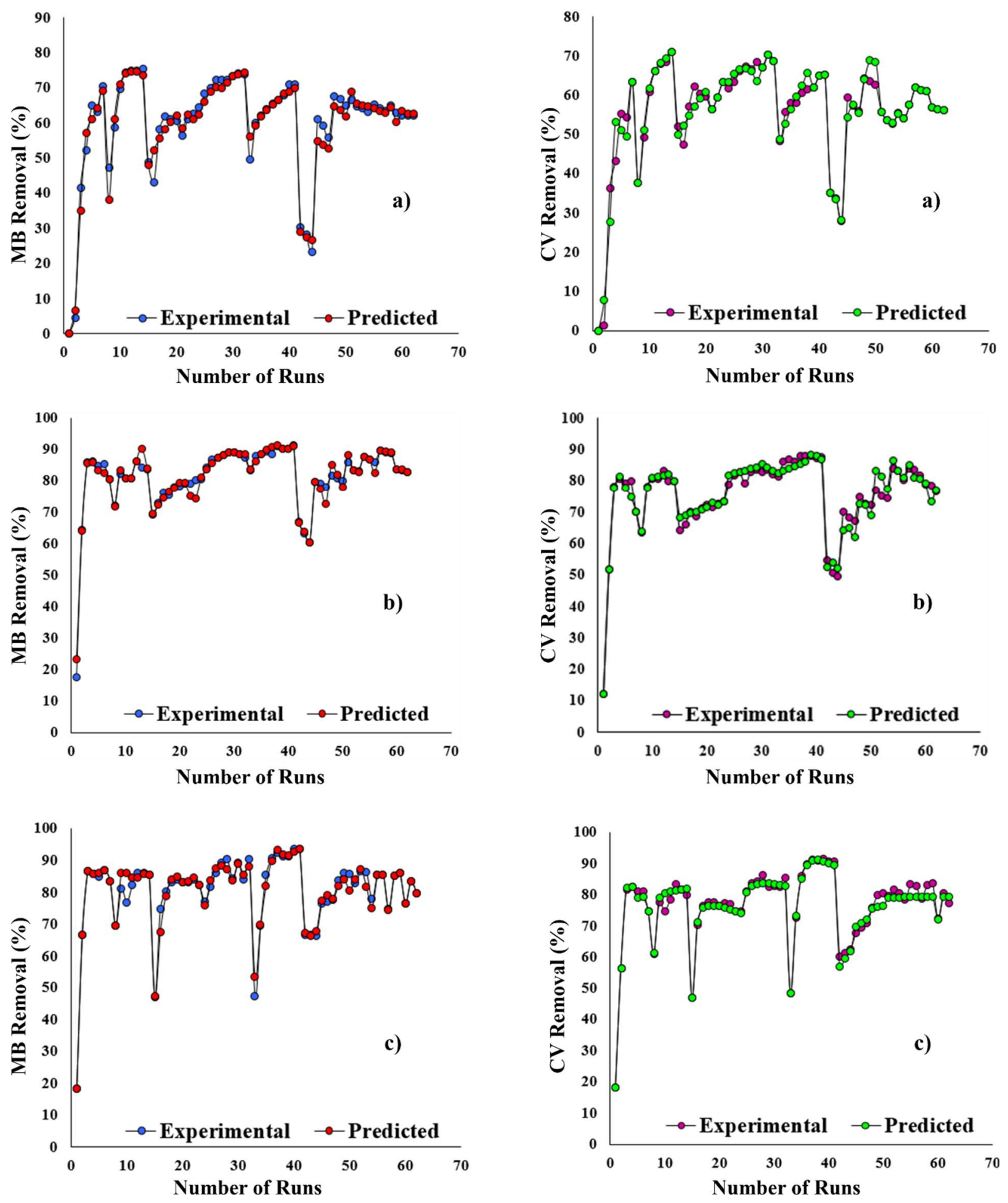

Fig. 10. Experimental and predicted normalized values of A) MB and B) CV removal efficiency by a) OP, b) NOP and c) SNOP for all data. 


\section{Conclusions}

The efficiency of orange peel (OP), NaOH-treated orange peel (NOP) and SDS-decorated NOP (SNOP) has been investigated for simultaneous removal of methylene blue (MB) and crystal violet (CV) dyes from binary system. The results of FESEM and FTIR analyses indicated that the functional groups and morphology of OP altered after treatment by $\mathrm{NaOH}$ and SDS and higher removal percentage of dyes obtained using modified samples (NOP and SNOP). The obtained thermodynamics parameters showed that the adsorption process of dyes is exothermic in nature and negative values of activation energy $\left(E_{a}\right)$ proved that lower solution temperature favors for dye adsorption onto the prepared biosorbents. The pseudo-second-order kinetic model showed the best fitting with the experimental data. Desorption tests were carried out in the presence of $\mathrm{H}_{2} \mathrm{O}$ and $\mathrm{HCl}\left(0.1\right.$ mol. $\left.\mathrm{L}^{-1}\right)$ and the obtained results confirmed that the main mechanism for dyes removal was ion exchange. The effect of different parameters like: solution $\mathrm{pH}$, adsorbent dose, initial concentration of dyes, contact time and temperature was studied using artificial neural network (ANN) model as an intelligent tool. The designed artificial neural network model for simulation of dyes removal in binary system was in good agreement with experimental data.

\section{Acknowledgment}

The authors wish to express their appreciation to the University of Tehran for financial support of the present study. 


\section{References}

[1] M. Abbas, M. Adil, S. Ehtisham-ul-Haque, B. Munir, M. Yameen, A. Ghaffar, G.A. Shar, M. Asif Tahir, M. Iqbal, Vibrio fischeri bioluminescence inhibition assay for ecotoxicity assessment: A review, Sci. Total Environ. 626 (2018) 1295-1309.

https://doi.org/10.1016/j.scitotenv.2018.01.066.

[2] L. Bulgariu, L.B. Escudero, O.S. Bello, M. Iqbal, J. Nisar, K.A. Adegoke, F. Alakhras, M. Kornaros, I. Anastopoulos, The utilization of leaf-based adsorbents for dyes removal: A review, J. Mol. Liq. 276 (2019) 728-747. https://doi.org/10.1016/J.MOLLIQ.2018.12.001.

[3] M.A.M. Salleh, D.K. Mahmoud, W.A.W.A. Karim, A. Idris, Cationic and anionic dye adsorption by agricultural solid wastes: A comprehensive review, Desalination. 280 (2011) 1-13. https://doi.org/10.1016/J.DESAL.2011.07.019.

[4] M. Iqbal, Vicia faba bioassay for environmental toxicity monitoring: a review, Chemosphere. 144 (2016) 785-802. https://doi.org/10.1016/j.chemosphere.2015.09.048.

[5] G.O. El-Sayed, Removal of methylene blue and crystal violet from aqueous solutions by palm kernel fiber, Desalination. 272 (2011) 225-232.

https://doi.org/10.1016/J.DESAL.2011.01.025.

[6] Y. Dai, Q. Sun, W. Wang, L. Lu, M. Liu, J. Li, S. Yang, Y. Sun, K. Zhang, J. Xu, W. Zheng, Z. Hu, Y. Yang, Y. Gao, Y. Chen, X. Zhang, F. Gao, Y. Zhang, Utilizations of agricultural waste as adsorbent for the removal of contaminants: A review, Chemosphere. 211 (2018) 235-253. https://doi.org/10.1016/J.CHEMOSPHERE.2018.06.179.

[7] Y. Zhou, J. Lu, Y. Zhou, Y. Liu, Recent advances for dyes removal using novel adsorbents: A review, Environ. Pollut. 252 (2019) 352-365.

https://doi.org/10.1016/J.ENVPOL.2019.05.072.

[8] A.A. Siyal, M.R. Shamsuddin, M.I. Khan, N.E. Rabat, M. Zulfiqar, Z. Man, J. Siame, K.A. Azizli, A review on geopolymers as emerging materials for the adsorption of heavy metals and dyes, J. Environ. Manage. 224 (2018) 327-339.

https://doi.org/10.1016/J.JENVMAN.2018.07.046.

[9] M.A. Khan, S.M. Wabaidur, M.R. Siddiqui, A.A. Alqadami, A.H. Khan, Silicomanganese fumes waste encapsulated cryogenic alginate beads for aqueous environment de-colorization, J. Clean. Prod. 244 (2020) 118867.

https://doi.org/10.1016/j.jclepro.2019.118867.

[10] A. Regti, A. El Kassimi, M.R. Laamari, M. El Haddad, Competitive adsorption and optimization of binary mixture of textile dyes: A factorial design analysis, J. Assoc. Arab Univ. Basic Appl. Sci. 24 (2017) 1-9. https://doi.org/10.1016/j.jaubas.2016.07.005.

[11] L.S. Chan, W.H. Cheung, S.J. Allen, G. McKay, Equilibrium adsorption isotherm study of binary basic dyes on to bamboo derived activated carbon, HKIE Trans. 24 (2017) 182192. https://doi.org/10.1080/1023697X.2017.1375434.

[12] M.A. Khan, M. Otero, M. Kazi, A.A. Alqadami, S.M. Wabaidur, M.R. Siddiqui, Z.A. Alothman, S. Sumbul, Unary and Binary Adsorption Studies of Lead and Malachite Green onto a Nanomagnetic Copper Ferrite/Drumstick Pod Biomass Composite, J. Hazard. 
Mater. 365 (2019) 759-770. https://doi.org/https://doi.org/10.1016/j.jhazmat.2018.11.072.

[13] W. Li, B. Mu, Y. Yang, Feasibility of industrial-scale treatment of dye wastewater via bioadsorption technology, Bioresour. Technol. 277 (2019) 157-170.

https://doi.org/10.1016/J.BIORTECH.2019.01.002.

[14] B.T. Huy, C.T.B. Thao, V. Dao, N.T.K. Phuong, Y. Lee, A Mixed-Metal

Oxides/Graphitic Carbon Nitride: High Visible Light Photocatalytic Activity for Efficient Mineralization of Rhodamine B, Adv. Mater. Interfaces. 4 (2017) 1700128. https://doi.org/10.1002/admi.201700128.

[15] V.-D. Dao, L.L. Larina, H.-S. Choi, Suppression of charge recombination in dyesensitized solar cells using the plasma treatment of fluorine-doped tin oxide substrates, J. Electrochem. Soc. 162 (2015) H903-H909. https://doi.org/10.1149/2.0851512jes.

[16] O. Chidi, R. Kelvin, Surface interaction of sweet potato peels (Ipomoea batata) with Cd (II) and $\mathrm{Pb}$ (II) ions in aqueous medium, Chem. Int. 4 (2018) 221-229.

[17] J. Huang, N.R. Kankanamge, C. Chow, D.T. Welsh, T. Li, P.R. Teasdale, Removing ammonium from water and wastewater using cost-effective adsorbents: A review, J. Environ. Sci. 63 (2018) 174-197. https://doi.org/10.1016/J.JES.2017.09.009.

[18] M. Shi, L. Yang, Z. Wei, W. Zhong, S. Li, J. Cui, W. Wei, Humic Acid Removal by Combining the Magnetic Property of Maghemite with the Adsorption Property of Nanosized Hydroxyapatite, J. Dispers. Sci. Technol. 37 (2016) 1724-1737. https://doi.org/10.1080/01932691.2016.1139462.

[19] M. Fazal-ur-Rehman, Methodological trends in preparation of activated carbon from local sources and their impacts on production: A review, Chem. Int. 4 (2019) 109-119. https://doi.org/https://doi.org/10.31221/osf.io/5m7fp.

[20] A. Aldawsari, M.A. Khan, B.H. Hameed, Z.A. AlOthman, M.R. Siddiqui, A.Y.B.H. Ahmed, I.H. Alsohaimi, Development of activated carbon from phoenix dactylifera fruit pits: Process optimization, characterization, and methylene blue adsorption, Desalin. Water Treat. 62 (2017) 273-281. https://doi.org/10.5004/dwt.2017.0529.

[21] S.M. Wabaidur, M.A. Khan, M.R. Siddiqui, M. Otero, B.H. Jeon, Z.A. Alothman, A.A.H. Hakami, Oxygenated functionalities enriched MWCNTs decorated with silica coated spinel ferrite - A nanocomposite for potentially rapid and efficient de-colorization of aquatic environment, J. Mol. Liq. 317 (2020) 113916.

https://doi.org/10.1016/j.molliq.2020.113916.

[22] M.A. Khan, Momina, M.R. Siddiqui, M. Otero, S.A. Alshareef, M. Rafatullah, Removal of rhodamine $\mathrm{b}$ from water using a solvent impregnated polymeric dowex $5 \mathrm{wx} 8$ resin: Statistical optimization and batch adsorption studies, Polymers (Basel). 12 (2020) 1-12. https://doi.org/10.3390/polym12020500.

[23] J. Wang, S. Wang, Preparation, modification and environmental application of biochar: A review, J. Clean. Prod. 227 (2019) 1002-1022. https://doi.org/10.1016/J.JCLEPRO.2019.04.282.

[24] M.C. Collivignarelli, A. Abbà, M. Carnevale Miino, S. Damiani, Treatments for color 
removal from wastewater: State of the art, J. Environ. Manage. 236 (2019) 727-745. https://doi.org/10.1016/J.JENVMAN.2018.11.094.

[25] S. Hokkanen, A. Bhatnagar, M. Sillanpää, A review on modification methods to cellulosebased adsorbents to improve adsorption capacity, Water Res. 91 (2016) 156-173. https://doi.org/10.1016/J.WATRES.2016.01.008.

[26] M. Naushad, M. Ali Khan, Z. Abdullah Alothman, M. Rizwan Khan, M. Kumar, Adsorption of methylene blue on chemically modified pine nut shells in single and binary systems: isotherms, kinetics, and thermodynamic studies, Desalin. Water Treat. 57 (2016) 15848-15861. https://doi.org/10.1080/19443994.2015.1074121.

[27] M.A. Khan, Z.A. Al Othman, M. Kumar, M.S. Ola, M.R. Siddique, Biosorption potential assessment of modified pistachio shell waste for methylene blue: thermodynamics and kinetics study, Desalin. Water Treat. 56 (2015) 146-160.

https://doi.org/10.1080/19443994.2014.934728.

[28] J. Široký, R.S. Blackburn, T. Bechtold, J. Taylor, P. White, Alkali treatment of cellulose II fibres and effect on dye sorption, Carbohydr. Polym. 84 (2011) 299-307.

https://doi.org/10.1016/J.CARBPOL.2010.11.037.

[29] A. Ebrahimian Pirbazari, E. Saberikhah, M. Badrouh, M.S. Emami, Alkali treated Foumanat tea waste as an efficient adsorbent for methylene blue adsorption from aqueous solution, Water Resour. Ind. 6 (2014) 64-80. https://doi.org/10.1016/J.WRI.2014.07.003.

[30] A. Ebrahimian Pirbazari, B. Fakhari Kisom, M. Ghamangiz Khararoodi, Anionic surfactant-modified rice straw for removal of methylene blue from aqueous solution, Desalin. Water Treat. 57 (2016) 18202-18216.

https://doi.org/10.1080/19443994.2015.1090919.

[31] S.M. Wabaidur, M.A. Khan, M.R. Siddiqui, Z.A. Alothman, S. Vasudevan, M.S. AlGamdi, I.H. Al-Sohami, Dodecyl sulfate chain anchored bio-char to sequester triaryl methane dyes: Equilibrium, kinetics, and adsorption mechanism, Desalin. Water Treat. 67 (2017) 357-370. https://doi.org/10.5004/dwt.2017.20447.

[32] M. Palmer, H. Hatley, The role of surfactants in wastewater treatment: Impact, removal and future techniques: A critical review, Water Res. 147 (2018) 60-72.

https://doi.org/10.1016/J.WATRES.2018.09.039.

[33] N.M. Mahmoodi, M. Taghizadeh, A. Taghizadeh, Mesoporous activated carbons of lowcost agricultural bio-wastes with high adsorption capacity: Preparation and artificial neural network modeling of dye removal from single and multicomponent (binary and ternary) systems, J. Mol. Liq. 269 (2018) 217-228. https://doi.org/10.1016/J.MOLLIQ.2018.07.108.

[34] A.M. Ghaedi, A. Vafaei, Applications of artificial neural networks for adsorption removal of dyes from aqueous solution: A review, Adv. Colloid Interface Sci. 245 (2017) 20-39. https://doi.org/10.1016/J.CIS.2017.04.015.

[35] H.E. Reynel-Avila, A. Bonilla-Petriciolet, G. de la Rosa, Analysis and modeling of multicomponent sorption of heavy metals on chicken feathers using Taguchi's 
experimental designs and artificial neural networks, Desalin. Water Treat. 55 (2015) 1885-1899. https://doi.org/10.1080/19443994.2014.937762.

[36] S.K. LAGERGREN, About the Theory of So-called Adsorption of Soluble Substances, Sven. Vetenskapsakad. Handingarl. 24 (1898) 1-39.

[37] G. Zhou, H. Tian, H. Sun, S. Wang, C.E. Buckley, Synthesis of carbon xerogels at varying sol-gel pHs, dye adsorption and chemical regeneration, Chem. Eng. J. 171 (2011) 13991405. https://doi.org/10.1016/J.CEJ.2011.05.054.

[38] Y.L. Tan, M.A. Islam, M. Asif, B.H. Hameed, Adsorption of carbon dioxide by sodium hydroxide-modified granular coconut shell activated carbon in a fixed bed, Energy. 77 (2014) 926-931. https://doi.org/10.1016/J.ENERGY.2014.09.079.

[39] A. Chham, E.H. Khouys, M. Oumam, The use of insoluble mater of Moroccan oil shale for removal of dyes from aqueous solution, Chem. Int. 4 (2018) 67-77.

[40] S. Wang, Z. Zhang, X. Yin, N. Wang, D. Chen, Influences of Nitrogen Application Levels on Properties of Humic Acids in Chernozem Amended with Different Types of Organic Materials, Sustainability. 11 (2019) 5405. https://doi.org/10.3390/su11195405.

[41] M. Mohamadi, E. Kowsari, V. Haddadi-Asl, M. Yousefzadeh, Fabrication, characterization and electromagnetic wave absorption properties of covalently modified reduced graphene oxide based on dinuclear cobalt complex, Compos. Part B Eng. 162 (2019) 569-579. https://doi.org/10.1016/J.COMPOSITESB.2019.01.032.

[42] N.H. Othman, N.H. Alias, M.Z. Shahruddin, N.F. Abu Bakar, N.R. Nik Him, W.J. Lau, Adsorption kinetics of methylene blue dyes onto magnetic graphene oxide, J. Environ. Chem. Eng. 6 (2018) 2803-2811. https://doi.org/10.1016/J.JECE.2018.04.024.

[43] A. Ebrahimian Pirbazari, S. Hashemian, A. Yousefi, Surfactant-modified wheat straw: preparation, characterization and its application for methylene blue adsorption from aqueous solution, J Chem Eng Process Technol. 6 (2015) 231. https://doi.org/http://dx.doi.org/10.4172/2157-7048.1000231.

[44] N.E. Ibisi, C.A. Asoluka, Use of agro-waste (Musa paradisiaca peels) as a sustainable biosorbent for toxic metal ions removal from contaminated water, Chem. Int. 4 (2018) 5259.

[45] A. Pirbazari, N. Pargami, N. Ashja, M. Emami, Surfactant-coated Tea Waste: Preparation, Characterization and its Application for Methylene Blue Adsorption from Aqueous Solution, J. Environ. Anal. Toxicol. 5 (2015) 1. https://doi.org/http://dx.doi.org/10.4172/2161-0525.1000310.

[46] A. Babaei, A. Khataee, E. Ahmadpour, M. Sheydaei, B. Kakavandi, Z. Alaee, Optimization of cationic dye adsorption on activated spent tea: Equilibrium, kinetics, thermodynamic and artificial neural network modeling, Korean J. Chem. Eng. 33 (2016) 1352-1361. https://doi.org/10.1007/s11814-014-0334-6.

[47] M. Duan, J. Wu, Y. Xiong, S. Fang, J. Chen, Characterization and differentiation of the adsorption behavior of crystal violet and methylene blue at the silica/water interface using near field evanescent wave, Soft Matter. 14 (2018) 7516-7525. 
https://doi.org/10.1039/c8sm01385c.

[48] S. Chakraborty, S. Chowdhury, P. Das Saha, Adsorption of Crystal Violet from aqueous solution onto NaOH-modified rice husk, Carbohydr. Polym. 86 (2011) 1533-1541. https://doi.org/10.1016/J.CARBPOL.2011.06.058.

[49] S. Ghezali, A. Mahdad-Benzerdjeb, M. Ameri, A.Z. Bouyakoub, Adsorption of 2, 4, 6trichlorophenol on bentonite modified with benzyldimethyltetradecylammonium chloride, Chem. Int. 4 (2018) 24-32.

[50] N. Nasuha, B.H. Hameed, A.T.M. Din, Rejected tea as a potential low-cost adsorbent for the removal of methylene blue, J. Hazard. Mater. 175 (2010) 126-132. https://doi.org/10.1016/J.JHAZMAT.2009.09.138.

[51] K.R. Chidi O, Surface interaction of sweet potato peels (Ipomoea batata) with Cd (II) and $\mathrm{Pb}$ (II) ions in aqueous medium, Chem. Int. 4 (2019) 221-229.

[52] A. Ariapad, M.A. Zanjanchi, M. Arvand, Efficient removal of anionic surfactant using partial template-containing MCM-41, Desalination. 284 (2012) 142-149. https://doi.org/10.1016/J.DESAL.2011.08.048.

[53] K. Legrouri, E. Khouya, H. Hannache, M. El Hartti, M. Ezzine, R. Naslain, Activated carbon from molasses efficiency for $\mathrm{Cr}$ (VI), $\mathrm{Pb}$ (II) and $\mathrm{Cu}$ (II) adsorption: a mechanistic study, Chem. Int. 3 (2017) 301-310.

[54] M. Gholami, M.T. Vardini, G.R. Mahdavinia, Investigation of the effect of magnetic particles on the Crystal Violet adsorption onto a novel nanocomposite based on $\kappa$ carrageenan-g-poly(methacrylic acid), Carbohydr. Polym. 136 (2016) 772-781. https://doi.org/10.1016/J.CARBPOL.2015.09.044.

[55] M. Laissaoui, Y. Elbatal, I. Vioque, G. Manjon, Adsorption of Methylene Blue on bituminous schists from Tarfaya-Boujdour, Chem. Int. 3 (2017) 343-352.

[56] G. Bayramoglu, B. Altintas, M.Y. Arica, Synthesis and characterization of magnetic beads containing aminated fibrous surfaces for removal of Reactive Green 19 dye: kinetics and thermodynamic parameters, J. Chem. Technol. Biotechnol. 87 (2012) 705-713. https://doi.org/10.1002/jctb.3693.

[57] V.K. Gupta, A. Mittal, V. Gajbe, Adsorption and desorption studies of a water soluble dye, Quinoline Yellow, using waste materials, J. Colloid Interface Sci. 284 (2005) 89-98. https://doi.org/10.1016/J.JCIS.2004.09.055.

[58] V.. Gupta, I. Ali, Suhas, D. Mohan, Equilibrium uptake and sorption dynamics for the removal of a basic dye (basic red) using low-cost adsorbents, J. Colloid Interface Sci. 265 (2003) 257-264. https://doi.org/10.1016/S0021-9797(03)00467-3.

[59] M.M.R. Williams, The mathematics of diffusion: By J. Crank. Clarendon Press, Oxford, $£$ 13.50, 1975, 414 pp, in: Pergamon, 1977: pp. 205-206.

[60] W.J. Weber, J.C. Morris, Kinetics of Adsorption on Carbon from Solution, J. Sanit. Eng. Div. 89 (1963) 31-60. 
[61] R.R. Karri, J.N. Sahu, B.C. Meikap, Improving efficacy of Cr (VI) adsorption process on sustainable adsorbent derived from waste biomass (sugarcane bagasse) with help of ant colony optimization, Ind. Crops Prod. 143 (2020) 111927.

https://doi.org/10.1016/j.indcrop.2019.111927.

[62] I.A.W. Tan, B.H. Hameed., Adsorption Isotherms, Kinetics, Thermodynamics and Desorption Studies of Basic Dye on Activated Carbon Derived from Oil Palm Empty Fruit Bunch, J. Appl. Sci. 10 (2010) 2565-2571. https://doi.org/10.3923/jas.2010.2565.2571.

[63] Y. Liu, C. Yan, Z. Zhang, H. Wang, S. Zhou, W. Zhou, A comparative study on fly ash, geopolymer and faujasite block for $\mathrm{Pb}$ removal from aqueous solution, Fuel. 185 (2016) 181-189. https://doi.org/10.1016/J.FUEL.2016.07.116.

[64] A.M. Aljeboree, A.F. Alkaim, A.H. Al-Dujaili, Adsorption isotherm, kinetic modeling and thermodynamics of crystal violet dye on coconut husk-based activated carbon, Desalin. Water Treat. 53 (2015) 3656-3667. https://doi.org/10.1080/19443994.2013.877854.

[65] Y.-S. Ho, Isotherms for the sorption of lead onto peat: comparison of linear and non-linear methods., Polish J. Environ. Stud. 15 (2006).

[66] S. Yang, M. Gao, Z. Luo, Q. Yang, The characterization of organo-montmorillonite modified with a novel aromatic-containing gemini surfactant and its comparative adsorption for 2-naphthol and phenol, Chem. Eng. J. 268 (2015) 125-134. https://doi.org/10.1016/J.CEJ.2015.01.060.

[67] E. Aranda-García, E. Cristiani-Urbina, Kinetic, Equilibrium, and Thermodynamic Analyses of Ni(II) Biosorption from Aqueous Solution by Acorn Shell of Quercus crassipes, Water, Air, Soil Pollut. 229 (2018) 119. https://doi.org/10.1007/s11270-0183775-4.

[68] L. Bulgariu, M. Rățoi, D. Bulgariu, M. Macoveanu, Equilibrium Study of Pb (II) and Hg (II) Sorption from Aqueous Solutions by Moss Peat., Environ. Eng. Manag. J. 7 (2008). https://doi.org/10.30638/eemj.2008.073.

[69] J.M. Horsfall, A.I. Spiff, Effects of temperature on the sorption of $\mathrm{Pb} 2+$ and $\mathrm{Cd} 2+$ from aqueous solution by Caladium bicolor (Wild Cocoyam) biomass, Electron. J. Biotechnol. 8 (2005) 43-50. https://doi.org/10.4067/S0717-34582005000200005.

[70] M. Al-Ghouti, M.A.M. Khraisheh, M.N.M. Ahmad, S. Allen, Thermodynamic behaviour and the effect of temperature on the removal of dyes from aqueous solution using modified diatomite: A kinetic study, J. Colloid Interface Sci. 287 (2005) 6-13. https://doi.org/10.1016/j.jcis.2005.02.002.

[71] Y. Shi, Z. Xue, X. Wang, L. Wang, A. Wang, Removal of methylene blue from aqueous solution by sorption on lignocellulose-g-poly(acrylic acid)/montmorillonite threedimensional cross-linked polymeric network hydrogels, Polym. Bull. 70 (2013) 11631179. https://doi.org/10.1007/s00289-012-0898-4.

[72] M. Tanzifi, S.H. Hosseini, A.D. Kiadehi, M. Olazar, K. Karimipour, R. Rezaiemehr, I. Ali, Artificial neural network optimization for methyl orange adsorption onto polyaniline nano-adsorbent: Kinetic, isotherm and thermodynamic studies, J. Mol. Liq. 244 (2017) 
189-200. https://doi.org/10.1016/J.MOLLIQ.2017.08.122.

[73] M. Shanmugaprakash, V. Sivakumar, Development of experimental design approach and ANN-based models for determination of $\mathrm{Cr}(\mathrm{VI})$ ions uptake rate from aqueous solution onto the solid biodiesel waste residue, Bioresour. Technol. 148 (2013) 550-559. https://doi.org/10.1016/J.BIORTECH.2013.08.149.

[74] M.. Rafiq, G. Bugmann, D.. Easterbrook, Neural network design for engineering applications, Comput. Struct. 79 (2001) 1541-1552. https://doi.org/10.1016/S00457949(01)00039-6.

[75] U. Özdemir, B. Özbay, S. Veli, S. Zor, Modeling adsorption of sodium dodecyl benzene sulfonate (SDBS) onto polyaniline (PANI) by using multi linear regression and artificial neural networks, Chem. Eng. J. 178 (2011) 183-190.

https://doi.org/10.1016/J.CEJ.2011.10.046.

[76] N. Altinkok, R. Koker, Mixture and pore volume fraction estimation in A12O3/SiC ceramic cake using artificial neural networks, Mater. Des. 26 (2005) 305-311. https://doi.org/10.1016/J.MATDES.2004.06.012.

[77] M.A. Chamjangali, M. Ashrafi, QSAR study of necroptosis inhibitory activities (EC50) of $[1,2,3]$ thiadiazole and thiophene derivatives using Bayesian regularized artificial neural network and calculated descriptors, Med. Chem. Res. 22 (2013) 392-400. https://doi.org/10.1007/s00044-012-0027-9.

[78] B.B. Drawanz, C.S. Ribeiro, H.G. Masteloto, P.D. Neuenfeldt, C.M.P. Pereira, G.M. Siqueira, W. Cunico, Sonochemistry: A good, fast and clean method to promote the synthesis of 5-arylidene-2,4-thiazolidinediones, Ultrason. Sonochem. 21 (2014) 16151617. https://doi.org/10.1016/J.ULTSONCH.2014.04.013.

[79] Y.A. Mustafa, G.M. Jaid, A.I. Alwared, M. Ebrahim, The use of artificial neural network (ANN) for the prediction and simulation of oil degradation in wastewater by AOP, Environ. Sci. Pollut. Res. 21 (2014) 7530-7537. https://doi.org/10.1007/s11356-0142635-z. 